\title{
The Renin-Angiotensin-Aldosterone System in Renal and Cardiovascular Disease and the Effects of its Pharmacological Blockade
}

Manuel Macía Heras, Nieves del Castillo Rodríguez and Juan F. Navarro González*

Department of Nephrology and Research Unit, University Hospital Nuestra Señora de Candelaria, 38010 Santa Cruz de Tenerife, Spain

\begin{abstract}
Cardiovascular disease (CVD) and chronic kidney disease (CKD) have become leading health problems worldwide. In addition, both conditions have relevant interrelatioships: cardiovascular disease may promote the development and progression of CKD, whereas CKD is a cardiovascular risk factor per se and potentiate the harmful effects of other cardiovascular risk factors. In addition, a critical common pathogenic and pathophysiologic factor in CVD and CKD is the renin-angiotensin-aldosterone system (RAAS). Moreover, from a therapeutic perspective, blockade of RAAS is a pivotal strategy in the treatment, control and prevention of CVD and CKD.
\end{abstract}

Keywords: Cardiovascular disease; Chronic kidney disease; Reninangiotensin-aldosterone system; Inflammation; Polymorphisms

\section{Introduction}

Cardiovascular disease (CVD) represents a leading health problem and a significant economic burden on society. It is the leading cause of death in the U.S., accounting for more than $35 \%$ of deaths [1]. Significant vascular risk factors for CVD include hypertension, diabetes, dyslipidemia, tobacco use, microalbuminuria, glomerular filtration rate (GFR) less than $60 \mathrm{ml} / \mathrm{m}$, a family history of CVD, physical inactivity, and obesity [2]. All of the risk factors mentioned contribute to a continuum of vascular disease, atherosclerosis, coronary artery disease, and left ventricular hypertrophy. The result is myocardial infarction with consequent remodeling of the myocardium, heart failure (HF), and arrhythmias, all contributing to premature death.

Together with the increasing importance of CVD, chronic kidney disease (CKD) has also been recognized as a major health problem in the industrialized world. In fact, a great prevalence of earlier stages of CKD has been inferred [3]. Based on data from the Third National Health and Nutrition Examination Survey, an awesome number of individuals in the US have significantly decreased kidney function. There are even more individuals with manifestations of kidney damage (particularly albuminuria) without a significant decrease in kidney function. It is evident that most patients with CKD do not progress to end-stage renal disease (ESRD), but likely succumb to CVD, which also is the leading cause of death for patients with ESRD on maintenance dialysis therapy. Micro- and macroalbuminuria are found in more than $9 \%$ of the adult population in the US and this percentage increase to $30 \%$ when evaluating people with hypertension and diabetes [4]. The concomitant presence of albuminuria, hypertension and diabetes confer a 2 - to 8 - fold increase in the risk of CV morbidity and mortality. Increased urinary albumin excretion rate has been recognized not only as an independent risk factor for CV but also for CKD [5]. At present there is consistent evidence that a significant delay in progression and even arrest of CKD is clinically achievable in many cases. Stated otherwise, patients with CKD should have their disease detected and treated well before the onset of kidney failure and the need for dialysis or transplantation.

The renin-angiotensin-aldosterone system (RAAS) is a wellknown regulator of blood pressure (BP) and determinant of targetorgan damage. It controls fluid and electrolyte balance through coordinated effects on the heart, blood vessels, and kidneys. Thus when overexpressed, RAAS has long been recognized as a significant contributor to CVD through increases in blood volume and arterial pressure, fibrosis, a prothrombotic state, and progression of vascular lesions. Overexpression of the RAAS leads to a variety of deleterious vascular effects [6]. Angiotensin II (AII) is the main effector of the RAAS due to its vasoconstrictor effect. AII may also directly contribute to $\mathrm{CV}$ damage by sustaining cell growth, inflammation, and fibrosis [7]. AII induces endothelial dysfunction via activation of important transcription factors, especially nuclear factor- $\kappa \beta$, thereby inducing pro-inflammatory phenotypes in vascular smooth muscle. AII also has a direct effect on smooth-muscle migration, vascular hypertrophy, and the synthesis and release of extracellular matrix composition, all of which contribute to vascular remodeling. Finally, AII receptor overexpression in adipose tissue induces inhibition of peroxisome proliferator-activated receptor-gamma (PPAR)- $\gamma$ activity, which may lead to insulin resistance [8]. Based on these data several experimental and clinical studies has suggest that blocking the system either with angiotensin-converting enzyme inhibitors (ACEIs) or AII receptor blockers (ARBs) are preferred agents in patients with either a CDV or $\mathrm{CKD}$, due to significant reductions in all-cause mortality, CV events and progression of renal disease [9]. Combined therapy with ACEI and ARB has also become more broadly adopted based primarily on biological plausibility that more intense blockade of the RAAS using multiple approaches are likely to be more effective [10].

The purpose of the present review is to present a general view of the multiple actions of RAAS and their more relevant components in the development and progression of CVD and CKD, together with an analysis of present treatments based on RAAS blockade including new drugs and their combinations as a fundamental strategies for reducing their impact on mortality and morbidity cause by these entities.

*Corresponding author: Juan F. Navarro González, MD, PhD, FASN, Research Unit, University Hospital Nuestra Señora de Candelaria, Carretera de Rosario, 145, 38010 Santa Cruz de Tenerife, Spain, Tel: +34922600566; Fax: +34922600562; E-mail: jnavgon@gobiernodecanarias.org

Received January 12, 2012; Accepted Feberuary 22, 2012; Published Feberuary 26, 2012

Citation: Macia-Heras M, Del Castillo-Rodriguez N, Navarro González JF (2012) The Renin-Angiotensin-Aldosterone System in Renal and Cardiovascular Disease and the Effects of its Pharmacological Blockade. J Diabetes Metab 3:171. doi:10.4172/2155-6156.1000171

Copyright: (c) 2012 Macia-Heras M, et al. This is an open-access article distributed under the terms of the Creative Commons Attribution License, which permits unrestricted use, distribution, and reproduction in any medium, provided the original author and source are credited. 
Citation: Macia-Heras M, Del Castillo-Rodriguez N, Navarro González JF (2012) The Renin-Angiotensin-Aldosterone System in Renal and Cardiovascular Disease and the Effects of its Pharmacological Blockade. J Diabetes Metab 3:171. doi:10.4172/2155-6156.1000171

\section{An Overview of RAAS}

The RAAS is directly involved in the regulation of BP, fluid volume, and vascular response to injury and inflammation [11]. The inappropriate activation of this system causes hypertension, fluid retention, and inflammatory, thrombotic, and atherogenic effects that may contribute to end-organ damage in the long term [12]. Although aldosterone (Aldo), renin, and several breakdown products of angiotensin I (AI) are also involved, most of the effects of the RAAS on target tissues are mediated by AII, which is generated both in the circulation and in the tissue (Figure 1).

In the classic pathway of the RAAS, renin is secreted from the juxtaglomerular apparatus of the kidney and acts on the circulating precursor angiotensinogen to generate AI [13]. Renin hydrolyzes the Leu10-Val11 bond of angiotensinogen, to generate the decapeptide AI (1-10). Angiotensin converting enzyme (ACE) present in the endothelium and tissues convert AI to the octapeptide AII. In the heart, kidneys, and brain, AII is also produced by non-ACE pathways involving chymases, cathepsin G, kallikrein-like enzymes and endopeptidases and seems to exert effects on target tissues that are even greater than the effects of centrally generated AII [14]. AII acts on the heart and the kidneys by binding to the $\mathrm{G}$ protein-coupled receptors type 1 (ATR1) and type 2 (ATR2). The ATR1 receptor mediates the more deleterious effects of AII - that is, vasoconstriction and cardiac and vessel hypertrophy. The ATR2 receptor regulates opposing effects. In addition to the conversion of AI to AII, ACE inactivates two vasodilator peptides, bradykinin and kallidin [13].
Recently, it has been discovered the ACE2, a homologue of ACE that is thought to counterbalance its actions. ACE2 cleaves AI and AII into the inactive angiotensin 1-9(A1-9), and the vasodilator and anti-proliferative angiotensin 1-7(A1-7), respectively [15]. Among all the active metabolites that are products of the RAAS, A(1-7) is the most important [16] and can also be produced by the action of tissue endopeptidases especially neprilysin on AI [16]. A(1-7) opposes the endogenous actions of tissue AII, provides cardiorenal protection by binding to the Mas protooncogene receptor [17]. Apart from its antiarrhythmogenic, antithrombotic and growth inhibitory effects, the most prominent effect of $\mathrm{A}(1-7)$ is the inhibition of the AII-induced vasoconstriction [18].

\section{Renin and Prorenin: The Concept and Actions}

Renin controls the first rate-limiting step of the system and cleaves angiotensinogen to the inactive decapeptide AI. The active octapeptide AII is formed from AI by the ACE. AII acts via ATR1 to increase arterial tone, adrenal Aldo secretion, renal sodium reabsorption, sympathetic neurotransmission, and cellular growth [19]. The renin activity is not only observed in plasma but also locally in tissues forming the basis for tisular RAAS, which are of prime importance for organ damage in CVD and diabetes [20]. However, since renin is hardly expressed outside the kidney it remained unclear how the enzyme reaches these sites, the recent discovery of the (pro)renin receptor has provided some clues to this issue [21].

The (pro) renin receptor is a protein that binds prorenin and renin in tissues, leading to their activation and, at the same time, to the

\section{Renin-Angiotensin-Aldosterone System: A 2011 overview}

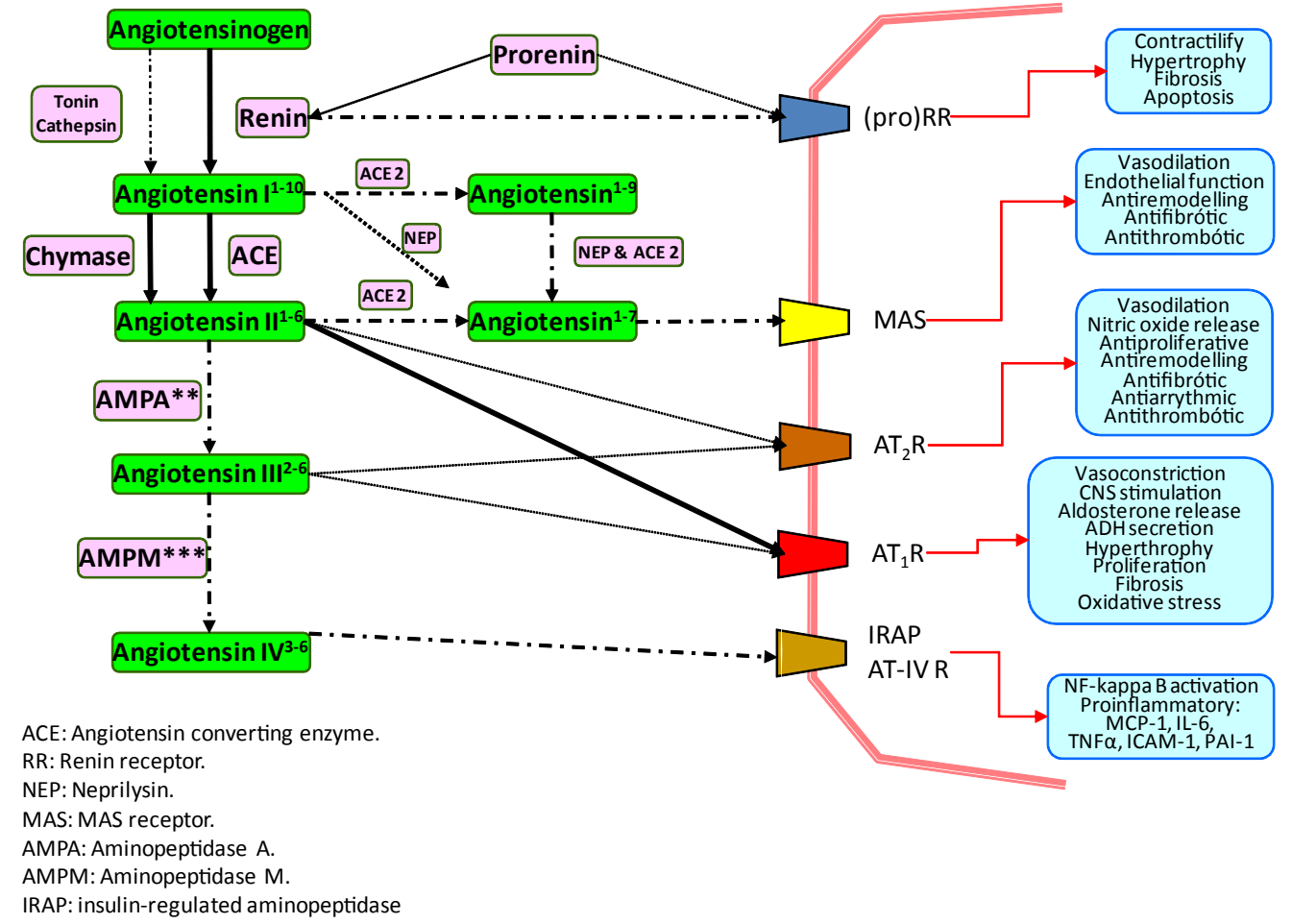

Figure 1: 
initiation of intracellular signaling [20]. The activation of local RAAS may play an important role in tissue damage induced by CVD and diabetes. The (pro) renin receptor is also called ATP6ap2 because it has been shown to be associated with vacuolar H+-ATPase involvement in vesicular acidification and signaling in cells [20]. Renin and (pro) renin bind the receptor in organs where (pro) renin is normally not generated leading to enzymatic activation and to intracellular signaling [22]. These data were ending the postulate of prorenin as a precursor devoid of any activity and were feeding the concept that (pro) renin can have angiotensin-independent actions. These actions are of particular importance in light of the fact that (pro)renin levels in plasma and tissues rise drastically after treatment with blockers of the RAAS such as ATR1 antagonists, ACEIs and, in particular, renin inhibitors [23]. (Pro)renin can be activated in a proteolytic or a non-proteolytic way. Proteolytic activation takes place mostly in the juxtaglomerular apparatus and is characterized by the removal of the prosegment. This process is irreversible and involves ill-defined proconvertases. Non-proteolytic activation is a conformational change resulting in the unfolding of the prosegment without any cleavage.

In physiological conditions, the plasma prorenin/renin ratio is around 10/1 and chronic stimulation of the juxtaglomerular apparatus decreases this ratio [24]. This is explained by the fact that (pro)renin is constitutively secreted whereas renin is stored in secretory vesicles within the juxtaglomerular apparatus in the kidney until release. The kidney seems to be the only renin-secreting organ and, more importantly, prorenin is also secreted by other organs. Organs such as reproductive tract, eye, adrenal and submandibular gland have been described as extrarenal (pro)renin sources [25]

The potential role of (pro)renin in pathology was first presented in human diabetic patients that display 3 to 7 -fold higher (pro)renin/ renin ratios in the blood [26]. However high (pro)renin levels are also found during pregnancy in the maternal plasma (where they can rise by a factor of 10) in the absence of any obvious tissue damage [21]. Also, several experimental studies reported (pro)renin overexpression in transgenic mice that is associated with mild hypertension, myocardial hypertrophy, and albuminuria without cardiac fibrosis or renal injury. These studies also discussed beneficial actions of (pro)renin, because in one line of their transgenic mice tissue damage is lower than expected from the level of BP [21]. In conclusion, the importance of (pro)renin in organ damage remains controversial.

\section{Angiotensin II}

AII is an octapeptide with a crucial role either in renal as in CVD that has deserve an intensive amount of investigation [27]. AII is considering the main effector of the RAAS, and as has been previously described is the product of a series of proteolytic reactions that starts with the cleavage of angiotensinogen by renin to form AI [13]. AII has a number of rapid effects, including vasoconstriction (which reduces the capacity of the vascular tree), increased Aldo secretion (which leads to salt retention), increased thirst and release of antidiuretic hormone (which leads to water conservation), increased myocardial contractility (which increases cardiac output), and increased activity of the sympathetic nervous system [28]. These effects can be viewed as a concerted response to support the circulation when it is challenged by intravascular volume depletion. In the long term, however, AII can cause trophic changes such as hyperplasia of the vascular smooth muscle and myocardium, deposition of extracellular matrix components, and sensitization of the blood vessels to low concentrations of vasoconstrictors; these changes can be viewed as a slow, structural remodeling of the cardiovascular system to compensate for prolonged volume contraction [29]

Although AII has emerged as a central mediator of the glomerular hemodynamics changes associated with progressive renal injury, several nonhemodynamics effects of angiotensin may be also important in renal and CVD progression [27]. These include coordinated upregulation of cytokines, cell adhesion molecules and profibrotic growth factors; induction of transforming growth factor-beta (TGF-beta) expression, a cytokine implicated in fibrotic and proliferative phenomena; increased synthesis of extracellular matrix proteins; stimulation of plasminogen activator inhibitor-1 (PAI-1) production by endothelial and vascular smooth muscle cell (VSMC); and macrophage activations and infiltrations [30]. PAI-1, the primary inhibitor of the fibrinolytic system and a potent anti-thrombolytic factor, has been identified to participate in the pathogenesis of both glomerulosclerosis and tubulointerstitial fibrosis [31]. As previously indicated AII augments the adrenal production of Aldo, a recently recognized contributor to renal injury that also may cause cardiac fibrosis [32].

AII also stimulates oxidative stress [33]. Thus the vasculature, interstitium, juxtaglomerular apparatus, and the distal nephron in the kidney have a rich expression of NADPH oxidase that generates superoxide anion, which is important in transducing the signal of AII to oxidative stress. Besides the direct effect of free radicals, they can also quench nitric oxide, an endothelium-dependent vascular relaxant, and thereby aggravate AII-induced vasoconstriction. Diverse vasoconstrictor mechanisms, including blockade of nitric oxide synthase, and activation of ATR1 and thromboxane receptors, can induce oxidative stress in hypertension [34]. The effects of superoxide anion and hydrogen peroxide on VSMC can cause vasoconstriction by quenching of nitric oxide and by nitric oxide synthase-independent mechanisms that include increased generation of endothelin-1.

\section{The angiotensin II receptors: A matter of balance}

Although several biologically active peptides are generated by the RAAS, its major actions are mediated by AII acting through its type 1 (ATR1) and type 2 (ATR2) receptors. Along with their effects to influence BP and hemodynamics, recent studies have provided evidence that angiotensin receptors influence a range of processes independent from hemodynamic effects [35]. AII acts in many tissues including kidney, heart, blood vessels, brain, and lymphatic organs, through binding and activation of receptors, which belong to the large family of G-coupled, 7 trans-membrane spanning receptors. The angiotensin receptors can be separated pharmacologically into two distinct classes: ATR1 and ATR2, and these receptors have been cloned and sequenced from many species. The consensus from studies using pharmacological ATR1 and ATR2 antagonists and genetic studies in mice is that the dominant cardiovascular actions of the RAAS are mediated by the ATR1. The ATR1 predominates in most tissues, on the contrary, expression of the ATR2 is highest during fetal development, decreasing in most tissues to very low levels in adults. In general, the functions of the ATR2 tend to oppose actions of the ATR1 [35].

The ATR1: The classical actions of the RAAS, and in particular its CV effects, are elicited by activation of ATR1. It has long been recognized that AT1R plays a critical role in the AII-mediated actions in the CV system (vasoconstriction, BP increase, water and sodium retention, growth promotion, fibrosis, inflammation) under physiological and pathological states. The efficacy of specific ARBs in treating hypertension, slowing progression of CKD, and reducing CV risk reflects the important role of this receptor in a variety of disorders. 
One well recognized function mediated by ATR1 is to trigger intense vasoconstriction [36]. These actions are mediated by direct effects of ATR1 in VSMC along with indirect effects of ATR1 activation of pathways in the central nervous system linked to peripheral vasoconstriction. Recently, it has been identified a novel signaling pathway linking ATR1 receptor activation to VSMC contraction where Rho kinase signaling plays a key role in ATR1-mediated vasoconstriction [37]. Also, it has been described that AT1 receptors have a profound impact on inflammation and immune responses by modifying cytokine production and inflammatory cell migration [35].

The ATR2: On the contrary of ATR1, the functional significance of ATR2 is much less characterized, due to its low levels of expression together with the very robust actions of the ATR1. Few studies have investigated the expression and the function of ATR2 in humans, particularly in the CV system [38]. Initial studies suggested that the ATR2 receptor did not have a major role in normal physiological regulation [35]. Subsequent studies, however, indicated that expression of the ATR2 increases under certain pathological conditions such as myocardial infarction [39], although this receptor is expressed to much lower levels in the heart compared with other tissues [38]. In the kidney, ATR2 are expressed mainly in interlobular arteries where it has been proposed that inhibits renin biosynthesis and AII formation and regulates glomerular blood flow and pressure natriuresis [40]. Both ATR1 and ATR2 play a role in the regulation of VSMC and extracellular matrix (ECM) components. Whereas ATR1 is associated with growth, inflammation and vasoconstriction, ATR2 may, in part, counteract these effects. ATR2 activation may directly antagonize ATR1 mediated actions by forming heterodimers with the ATR1 subsequently producing anti-inflammatory, antiapoptotic and BPlowering actions with beneficial consequences for CVD [41]. However, it has been shown recently that AII induced ATR1 signals may be mainly blocked by ATR2 signals through their negative cross-talk in the cytoplasm, rather than by the heterodimerization of both receptors on the cell surface [38].

One of the direct actions of ATR2 is that produce vasodilatation through several pathways [38]. ATR2 reduced the vascular tone of isolated resistance arteries from hypertensive diabetic patients chronically treated with an ARB, suggesting that unblocked AT2R stimulated by the increased AII in these individuals could participate in $\mathrm{BP}$ reduction induced by ARBs [42]. Along with the ATR2-mediated antigrowth and proapoptotic actions, the reduced vascular tone may be involved in the improvement of vascular remodeling observed in these high CV risk patients treated with ARBs [43]. Thus, ATR2 may participate in mechanisms whereby therapeutic use of ARBs induces CV protection. Although the exact role of ATR2 in human pathophysiology is still in need of elucidation, a growing body of evidence suggests that AT2R may be a potential therapeutic target in hypertension. Recently it has been developed a highly selective, nonpeptide ATR2 agonist (C21) [44]. In vivo studies has showed different actions including an improvement of cardiac function after myocardial infarction, amelioration of remodeling and reduced inflammatory responses [35].

\section{Aldosterone: New Actions in CVD and CKD}

Aldo is secreted by the zona glomerulosa under the influence of AII, potassium, and ACTH. The net effect is that Aldo functions to maintain normal sodium and potassium balance as well as BP and circulating blood volume. Aldo exerts its main effects on sodium and potassium balance by binding to the mineralocorticoid receptor (MCR) located in the distal convoluted tubule, connecting segment and cortical collecting duct in the kidney. However, at present the diverse actions of Aldo seems to be related to two different regulatory pathways, the genomic pathway which regulates the transport of sodium and potassium in epithelial cells; and the nongenomic pathway that acts increasing fibrosis, collagen deposition, inflammation, and remodeling of the heart and blood vessels, these affects are markedly increased in the presence of high sodium intake [45]. For its genomic effects in the kidney, Aldo binds to MCRs in the cytoplasm of the principal cells of the collecting duct with resultant stimulation of nuclear protein synthesis. This process involves a new protein synthesis, so it takes hours to generate the epithelial effect and can be blocked by an inhibitor of protein synthesis. In addition MCRs are also present in glomerular endothelial cells, mesangial cells and podocytes as well as the renal and systemic vascular endothelial tissues [46]. In recent years, nongenomic effects of Aldosterone have been demonstrated [47]. These effects can be observed within minutes and presumably involve plasma membrane MCRs that are present in many organs (heart, blood vessels, liver, $\beta$ cells of the pancreas, and glomerular mesangial cells). The cell-signaling pathways of these nongenomic effects have not been completely defined. Essentially, increased sodium chloride intake enhances these effects and renal epithelial sodium transport does not seem to be necessary for its presence [45]. Nongenomic effects of Aldo also include inflammation, oxidative stress, apoptosis, and fibrosis which are related to the NF- $\kappa B$ transcription factor [48].

\section{The aldosterone cardiovascular effects and the "escape" mechanism}

Aldo is known as a sodium-retaining hormone that is very important in circumstances with losses of total body sodium (e.g., diarrhea, vomiting, hemorrhage, excessive sweating, glucosuria, diuretics). Paradoxically, however, administration of large exogenous amounts of Aldo to normal individuals does not cause edema. After the initial sodium-retaining effect of Aldo, urinary sodium excretion increases to balance intake before any edema formation (the so-called "aldosterone escape" mechanism). In normal conditions "escape" mechanism involves increased sodium delivery to the distal collecting duct site of mineralocorticoid site of action. However, in edematous patients with cardiac failure who have an increase not only in extracellular fluid but also in total plasma volume yet the kidney continues to retain sodium in this situation the cause seems to be the failure of the "escape" mechanism. In fact the Aldo escape does not occur in HF and cirrhosis because of the neurohumoral effects that decrease distal sodium delivery [45]. Of importance, blockade of the genomic effect of Aldo necessitates dosages of mineralocorticoid antagonists that are sufficient to block competitively the elevated endogenous Aldo concentrations in patients with HF [49].

Two important clinical studies have demonstrated potential nongenomic effects of aldosterone: the RALES (dosage-finding Randomized Aldosterone Evaluation Study) performed in patients with severe cardiac failure which demonstrated that low daily dosages of spironolactone $(25 \mathrm{mg})$ did not increase urinary sodium excretion [50] and the EPHESUS (Eplerenone post-AMI Heart Failure Efficacy and Survival Study) where the mineralocorticoid antagonist eplerenone (mean $43 \mathrm{mg} / \mathrm{d}$ ) reduced mortality after acute myocardial infarction [51]. It seems reasonable to suggest that at least some of the results of the mortality of both studies are due to inhibition of nongenomic effects of aldosterone. Thus low-dosage mineralocorticoid antagonists are considering now standard of clinical care in advanced HF and acute myocardial infarction. One reason is the danger of hyperkalemia secondary to mineralocorticoid [52]. More recently the results of the 
ADHERE (Acute Decompensated Heart Failure Registry) indicated the need for better treatment for acute cardiac decompensation [53] shows that genomic dosages of mineralocorticoid antagonists are in need of study in patients who have decompensated $\mathrm{HF}$ and are receiving a lowpotassium diet and no potassium supplements. The diuretic resistance of loop diuretics common in these patients may be reversed with mineralocorticoid antagonists, and the resultant increased urinary potassium losses may also protect against any clinically relevant hyperkalemia in patients who have cardiac failure and receive the combination of ACEI and spironolactone [45].

\section{Aldosterone in CVD and hypertension}

Aldo plays a pathological role in CVD and kidney disease in part due to its mitogenic effects on a number of cell types in the systemic vasculature, heart and kidney [54]. Other mechanism involve in Aldo CV injury include inflammation, oxidative stress, activation and enhancement of AII and accelerated fibrosis [46]. After binding to the MCR, Aldo is translocated into the nucleus, in which the complex dissociates and binds to regulatory regions of multiple genes that stimulate production of proteins involved in both sodium and potassium transport as well as inflammation and oxidative stress.

There is evidence of a nongenomic effect of Aldo to injure the endothelium, which could contribute to elevated BP and be prevented by a mineralocorticoid antagonist [45]. The role of Aldo in hypertension was shown in three-drug-resistant hypertension. Thus in the ASCOT (Anglo-Scandinavian Cardiac Outcomes Trial) trial performed in patients with three-drug-resistant hypertension, 25 $\mathrm{mg} / \mathrm{d}$ spironolactone decreased mean systolic and diastolic BP [55]. Interestingly this trial also showed that decrements in BP were the same in three-drug-resistant hypertension in patients with and without primary hyperaldosteronism. Three-drug-resistant hypertension may also be associated, particularly in obese patients, with obstructive sleep apnea, although the relation of these finding with Aldo have not been evaluated.

\section{Aldosterone and CKD}

There are several pathogenetic factors in which Aldo, via the nongenomic pathway, may contribute to CKD. Experimental models of CKD have demonstrated a key role for Aldo-mediated glomerular and tubular injury and inflammation. This injury is mediated in part by activation of oxidative stress molecules, up-regulated in part by NADPH oxidase, including proinflammatory cytokines such as IL-6, MCP-1, ICAM-1, osteopontin and TGF-beta [56]. Both tubulointerstitial damage and glomerular injury, particularly of the podocytes, occurs secondary to this nongenomic effect of Aldo [45]. Blockade of the MCR using drugs like spironolactone and eplerenone attenuate or abrogate all these effects [57]. An interesting finding is that some of the beneficial effects of Aldo blockade are believed to be, in part, by improvement in endothelial dysfunction [57].

Also a correlation between proteinuria and plasma Aldo has been shown to occur in patients with CKD [58]. Moreover, spironolactone $(25 \mathrm{mg} / \mathrm{d})$ has been shown to reduce proteinuria in patients who had $\mathrm{CKD}$ and were already receiving an ACEI or ARB and this effect was more intense than addition of an ARB to an ACEI [59]. Studies in type 2 diabetes also have demonstrated that spironolactone decreases systolic and diastolic BP as well as urinary protein and albumin excretion as compared with placebo [60]. The mechanism by which Aldo blockade reduces proteinuria is incompletely understood.
Blockade of the MCR is accompanied by lowering of systemic BP that in turn is well known to lower proteinuria in patients with CKD and uncontrolled hypertension. However there are some evidence that in patients with diabetic nephropathy that the antiproteinuric effect of mineralocorticoid receptor blockade (MRB) is at least in part mediated by a direct effect on the glomerular basement membrane and is not dependent solely on reduction in systemic BP, glomerular filtration or dietary factors [57]. What is less well established is the effect of spironolactone on slowing the loss of GFR. However, a recent study shows that the monthly rate of decrease in estimated GFR at one year was significantly less in the spironolactone-treated group than in the placebo group [58].

\section{ACE 2 and A(1-7): New Insigths in their Role in CVD and Renal Disease}

The RAAS is composed of a number of different regulatory components and effectors molecules that facilitate the dynamic control of vascular function. Many of these components have opposing functions to accommodate a rapid but balanced response to specific triggers. Historically, ACE and AII have been the key focus for interventions targeting the RAAS. However, recent studies have also demonstrated the importance of ACE2 and $\mathrm{A}(1-7)$ in maintaining the balance of the RAAS, in both health and disease [61].

ACE2 is a type 1 integral membrane glycoprotein that is found in most tissues, with the highest expression observed in the kidney, the endothelium and in the heart [62]. In the CV system ACE2 may be more important than ACE in regulating local levels of AII and A(17) [61]. A(1-7) is an heptapeptide and is produced through hydrolysis of AII. It has been describe two biochemical pathways that participate on its formation: the first entails the hydrolysis of AI by the tissue endopeptidases; the second entails the cleavage of the Pro7-Phe8 bond of AII by ACE2, an exopeptidase which has also been shown to cleave AI into A(1-9). Recently a third pathway leading to the ultimate generation of $\mathrm{A}(1-7)$ may result from the discovery of an extended form of AI, the dodecapeptide angiotensin(1-12) [63]. A(1-7) has a receptor, Mas, a G-protein coupled receptor originally linked to modulation of growth regulating pathways involved in oncogenic effects [63].

Ferrario et al. established the basis and initial mechanisms for the inclusion of the $\mathrm{A}(1-7) / \mathrm{ACE} 2 / \mathrm{Mas}$ axis as a critical counter balancing component of the pressor pathway composed by the ACE, AII and its signaling action following binding to the AT1 receptor. Over the last decade, data continue to support the hypothesis that the pathological actions of AII on CV regulatory activity may in part result from a diminished expression or activity of the components of the $\mathrm{A}(1-7)$ / ACE2/Mas- R axis [64]. Experimental and clinical studies demonstrate a role for the $\mathrm{A}(1-7) / \mathrm{ACE} 2 / \mathrm{Mas}$ axis in the evolution of hypertension, the regulation of renal function, and the progression of renal disease including diabetic nephropathy. Additional evidence suggests that a reduction in the expression and activity of this vasodepressor component may be a critical factor in mediating the progression of CVD [63].

In summary the discovery that $\mathrm{A}(1-7)$ opposes the pressor, proliferative, profibrotic, and prothrombotic actions mediated by AII has contributed to the realization that the RAAS is composed of two opposing arms: the pressor arm constituted by the enzyme ACE, AII and the AT1R and the second arm, composed of ACE2, A(1-7), and the Mas receptor as the protein conveying the vasodilator, antiproliferative, antifibrotic, and antithrombotic effects of A(1-7) [63]. 


\section{ACE2 and A10-7 in CVD and hypertension}

RAAS has a critical pathophysiologic role in cardiac function and, in particular, the progression of HF. Its activation in the heart leads to both accelerated atherosclerosis and direct cardiac injury that result from the activation of a complex range of pathogenic pathways. Also several studies showed that actions leading to RAAS blockade were able to attenuate or prevent cardiac damage, independent of BP lowering. In the heart, ACE2 is the primary pathway for the metabolism of AII, its deficiency results in early cardiac hypertrophy, and progressive cardiac fibrosis, leading to diastolic dysfunction with aging and/or cardiac pressure overload $[61,65]$. The expression of ACE2 in the failing human heart is generally increased, consistent with the finding of elevated levels of A(1-7) in the same setting [66]. Recently, experimental studies in mice have shown beneficial cardiac effects with recombinant ACE2 (rAC2) [67]. The mechanism of rACE2 action results from an increase in systemic, not tissue, ACE2 activity and the lowering of plasma AII rather than the attendant increase in $\mathrm{A}(1-7)$. So it seems that increasing ACE2 activity may provide a new therapeutic target in states of AII overactivity by enhancing its degradation.

As previously said, activation of the RAAS constitutes a key mediator of hypertension. The antihypertensive efficacy of those agents that blocks the system is mediated not only by their ability to reduce AII or its signaling, but also by the ability of both to increase circulating levels of A(1-7) [61]. ACE2, which metabolizes AII and generates A(1$7)$, influences not only the development of hypertension, but also potentially the response to its treatment. A number of studies have demonstrated the altered regulation of ACE2 in various experimental models of hypertension. Moreover, interventions to augment the expression or activity of ACE2 have been shown to significantly reduce $\mathrm{BP}$ levels [67]. In experimental models $\mathrm{A}(1-7)$ has been related to the pathogenesis of human essential hypertension based on its counterregulatory actions that causes an antihypertensive effect [68]. Clinical studies supporting these favorable actions of $\mathrm{A}(1-7)$ show an increased excretion of $\mathrm{A}(1-7)$ in the urine of essential hypertensive patients whose BP was controlled by a 6-month treatment with captopril [69]. Additional studies showed that administration of irbesartan was associated with increases in plasma $\mathrm{A}(1-7)$ concentrations [70].

In summary all of these data suggest that is the balance of ACE and ACE2 in the heart, and their action to counterbalance AI and A(17) that appears to be the most important driving factor in progressive cardiac disease and hypertensive disease. The research done to-date continues to support the hypothesis that a decrease in the expression or activity of $A(1-7)$ renders the cardiovascular system more susceptible to the pathological actions of AII.

\section{$\mathrm{ACE} 2$ and $\mathrm{A}(1-7)$ in $\mathrm{CKD}$}

Multiple studies have documented that kidneys is a site at which an intrarenal RAAS participates in the regulation of glomerular-tubular balance in health and disease [71]. ACE2 is present in high levels in the adult kidney, predominantly expressed in the proximal tubule at the luminal brush border [61].

Experimental evidence has demonstrated several actions of ACE2 and $A(1-7)$ in the regulation of nephron function [72]. Also recent studies show that altered ACE2 expression or activity contributes to the progression of renal disease and diabetic nephropathy [61]. In most forms of CKD, including diabetes, ACE2 expression levels are reduced in tubules, but increased in glomeruli [73]. It is possible that this differential expression pattern of glomerular and tubular ACE2 is an important determinant for progressive renal disease. However there are some confounding effects of ACE2 related with some of the actions of $\mathrm{A}(1-7)$ on the kidney. Although $\mathrm{A}(1-7)$ is generally regarded as an antagonist of AII mediated injury and dysfunction [63] it has been recently observed that $\mathrm{A}(1-7)$ is able to induce epithelial-tomesenchymal transition of tubular cells, which potentially contributes to the renal accumulation of matrix proteins that is associated with progressive renal disease [61]. These data provide additional support for an important interaction among ACE2 and A(1-7) in multiple disease states.

\section{New Compounds of the RAAS}

The angiotensin peptides AI and II are susceptible to digestion at several sites by angiotensinases peptidases: aminopeptidases, carboxypeptidases, or endopeptidases. The resultant peptide fragments are found in the circulation, and have functions that might be distinct from those of AII [74]. Thus angiotensin III (the $2-8$ peptide) and angiotensin IV (the 3-8 peptide) are also produced by cleavage of AII. The functional role of AIII and IV is relatively unclear. AIII has functions identical although lee potent than AII whereas AIV can bind selectively to a novel receptor (ATR4) and stimulate release of PAI-1 [74] and playing a role in regulating local blood flow to the brain [75]. Also A(1$7)$ is susceptible of being metabolized by ACE and aminopeptidases to inactive fragments $\mathrm{A}(1-5), \mathrm{A}(1-4), \mathrm{A}(2-7)$ and $\mathrm{A}(3-7)$ [76]. There is a relatively new addition to the family of RAAS effectors, $\mathrm{A}(1-12)$ [77] that is produced directly from angiotensinogen by a non-renin enzyme. It contains the 12 amino acids from the $\mathrm{N}$-terminus of angiotensinogen and can act as a precursor for the generation of AII by chymase. The biological significance of these novel peptides is now being investigated in several laboratories.

\section{Agents that Block the RAAS: Their Effects on CVD and Renal Disease}

The RAAS has a pathogenic role in several edematous disorders, including cardiac disease, liver disease, drug-resistant hypertension, $\mathrm{CKD}$, the metabolic syndrome, and diabetes mellitus. The finding that AII and Aldo are proinflammatory, profibrotic, and can cause oxidative injury, has led to the development of several agents that inhibit the RAAS. The pharmacological inhibition of the RAAS can be obtained through three different basic mechanisms: (1) inhibition of AII generation from AI, achieved through inhibition of ACE; (2) inhibition of the action of AII at the level of its receptor(s); and (3) inhibition of AI generation from angiotensinogen obtained by direct inhibition of renin. Thus drugs acting on the RAAS include: the direct renin inhibitors (DRIs), the ACEIs, the ARBs, the aldosterone-receptor antagonists (ARAs) and a new class of combined ACE and neutral endopeptidase (NEP) inhibitors, called the vasopeptidase inhibitors (VPIs) (Figure 2).

Several mechanisms contribute to the beneficial effects of RAAS blockers in $\mathrm{CV}$ and renal therapy: the hemodynamic consequences of AII neutralization and the suppression of the AII-dependent generation of growth-promoting cytokines, free oxygen radicals, and fibrosis mediators in tissues [6]. However, the various methods used to inhibit the RAAS differ in terms of their biochemical effects [78]. Although single-site RAAS inhibitors allow mainly for inhibition of both the circulating and tissue RAAS, depending on their primary target and the distribution of the drug, alternative mechanisms may be involved in their overall pharmacodynamic effect. AT1R antagonists block the effects of AII generated by pathways other than ACE, such 


\section{Inhibition of Renin-Angiotensin-System: A 2011 overview.}

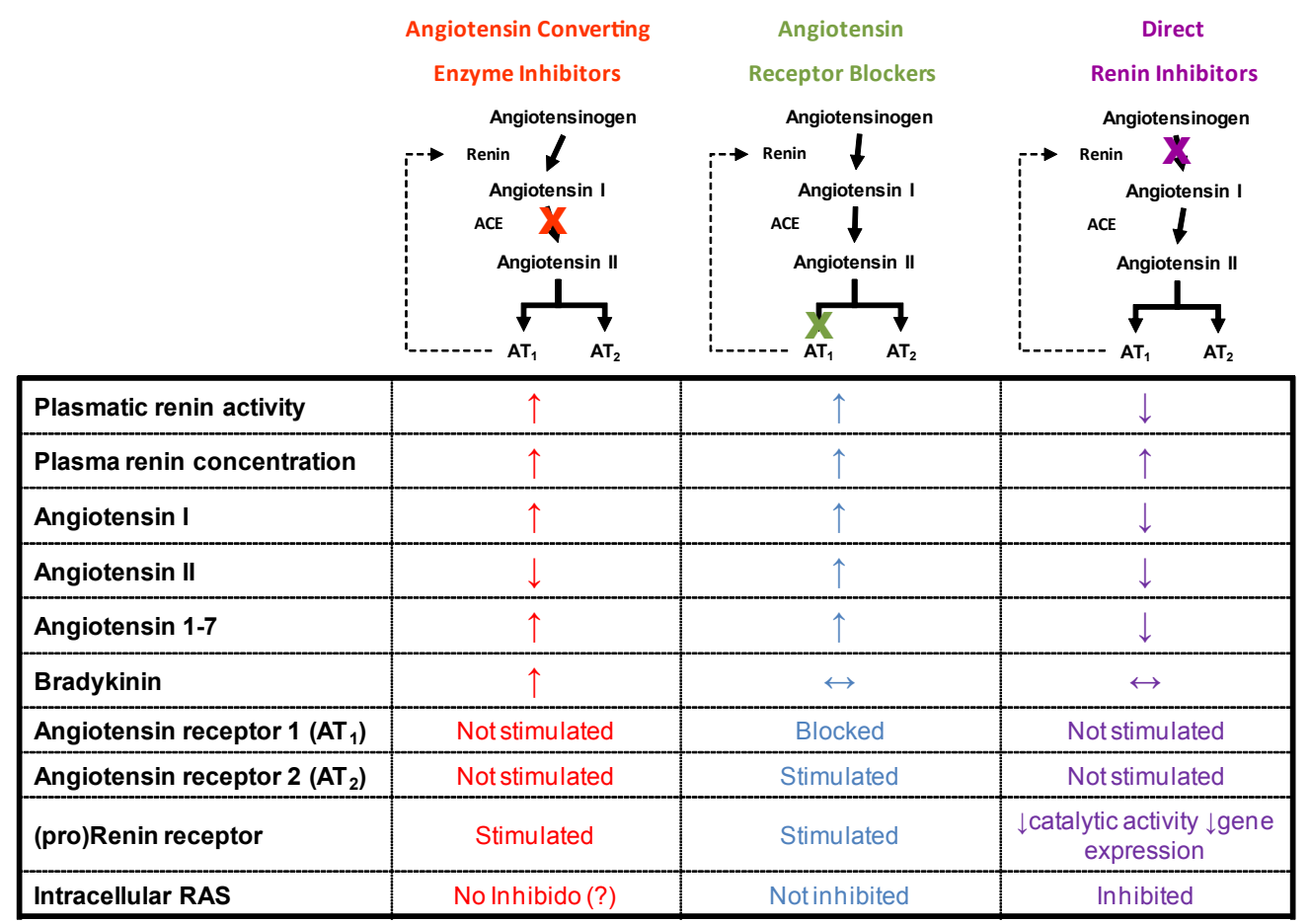

Figure 2:

as chymotrypsin-like angiotensin-generating enzyme or chymase. In some organs, such as the kidneys, heart and blood vessels AII continues to be produced in patients treated with ACEIs. Non-ACE pathways may be activated in some pathologic situations. ACEIs induce the accumulation of vasodilator and natriuretic peptides, such as $\mathrm{BK}$ and $\mathrm{A}(1-7)$. During chronic ACE inhibition, increases in $\mathrm{A}(1-7)$ levels may enhance the vasodilator activity of BK by stimulating NO release [63]. ARBs antagonize AT1R and block the effects of AII generated by pathways other than ACE, such as chymotrypsin-like angiotensingenerating enzyme or chymase. In some organs, such as the kidneys, heart and blood vessels AII continues to be produced in patients treated with ACEIs [79]. By blocking AT1R ARBs also stimulate potentially functional ATR2s, which then may trigger a vasodilator and natriuretic cascade involving bradikinine (BK), nitric oxide (NO), and cyclic guanosine monophosphate and other AII receptors, the functions of which remain unclear [38]. Little is known about the physiologic consequences of activating these receptors but if their activation should prove to be deleterious, an issue that remains seriously debated, then renin inhibitors would have clinical advantages over alternative RAAS inhibitors [80,81]. Also during chronic ACE inhibition, there is an increase in levels of the hemoregulatory peptide N-acetyl-Ser-AspLys-Pro (AcSDKP) that may have beneficial cardiac and renal effects. AcSDKP has been shown to have an antiproliferative and antifibrotic effect on the heart and the kidney in vitro and in vivo [79].

Blockade of the RAAS with ACEIs, ARBs or a combination of these drugs has become one of the most successful therapeutic approaches in medicine [82]. The beneficial effects of BP-lowering treatments on the risks of major CV events are well established [83]. The interruption of the RAAS with the above mentioned agents or its combination has been shown to be an effective strategy for lowering BP. However the organprotecting effects of RAAS inhibitors are thought to be independent of their effects on BP and physicians should keep in mind that the RAAS has a critically important role in maintaining homeostasis of body fluid volume and BP. Several trials with drugs operating on ACE and on AII receptors have shown their benefits beyond BP control, such as preventing progression of renal dysfunction [84] and decreasing CVD mortality and morbidity $[85,86]$.

Most of the evidence pertaining to RAAS inhibition and CVr and kidney protection was derived from placebo-controlled renal clinical trials (RCTs) of ACEI or ARB with relatively few RCTs evaluating the comparative efficacy of ACEI versus ARB head to head $[87,88]$. Recently, a systematic review of the literature that directly compare the effects of taking ACEI versus ARB on patient-level CV and kidney outcomes in a large number of albuminuric patients showed that the two classes of RAAS inhibitors were comparable with respect to all CV and kidney outcomes evaluated [84]. These findings are in keeping with those of a previous meta-analysis, which reported that the magnitudes of reduction in proteinuria following ARBs and ACEIs therapy are similar [89]. Although monotherapy with ACEIs and ARBs resulted in significant improvements in both CV and kidney end points, these did not translate into a consistent reduction in all-cause mortality. Alternatively, the beneficial effects of ACEIs and ARBs on CV and kidney outcomes might have been counterbalanced by deleterious effects, such as hyperkalemia [90].

\section{Angiotensin converting enzyme inhibitors (ACEIs)}

Early studies of the mechanisms of conversion of AI to II, and of bradykinin hydrolysis, led to the isolation (from snake venom) and 
synthesis of small peptide inhibitors of ACE (kininase II) [91,13]. The ACEIs are a heterogeneous group, both in terms of chemical structure and pharmacokinetics. They are unified only in their ability to associate competitively with the active binding site of ACE. They are categorized into three subgroups according to their mode of metabolism: active compounds that are metabolized to form active metabolites, (eg captopril); prodrugs that require hepatic metabolism to form an active compound, (eg enalapril maleate, fosinopril, perindopril, quinapril, ramipril and trandolapril); and active compounds that are excreted unchanged, (eg lisinopril). However, ACEIs also differ within these groups in their bioavailability, protein binding, lipid solubility, affinity to the ACE binding site, duration of onset, half-life and potency [13]. While the onset and duration of action are important considerations in terms of dosing, there is no evidence to suggest that the other differing pharmacokinetic properties are of clinical significance. Perhaps the best evidence in support of this comes from experience with captopril. Despite being the least potent of the class and weakly lipophilic, when used at an appropriate dose it has been shown in the SAVE and ISIS- 4 trials to be similar to other ACEIs in reducing mortality and morbidity in the HF and postinfarction settings [92,93]. ACEIs proved to be highly successful in the treatment of hypertension and related target-organ damage, including left ventricular hypertrophy, $\mathrm{HF}$, and postmyocardial infarction left-ventricular remodeling, renal insufficiency, and diabetes with proteinuria. After the introduction of captopril for clinical use [91,13], several ACEIs have been developed, and many have been approved for the treatment of hypertension, HF, diabetic nephropathy, and/or left ventricular dysfunction. ACEIs differ in their ability to penetrate and bind tissue sites for prolonged periods [13].

There are a plethora of reported adverse reactions ascribed to ACEIs. Those most clinically important are hypotension, renal impairment, hyperkalaemia, cough and angioedema. ACEI induced hypotension is accentuated by concomitant hypovolemia, unstable cardiac failure or hyponatraemia. This is reflected in the literature, which indicates that, the incidence of ACEI-related hypotension in HF $(14 \%)$ and acute MI $(17 \%)$ patients $[92,93]$ is far greater than that in the HOPE (Heart Outcomes Prevention Evaluation study) and EUROPA (EUropean trial on Reduction Of cardiac events with Perindopril in stable coronary Artery disease) populations (1.9 and $1.0 \%$ respectively) and is even less in uncomplicated hypertension $[94,95]$. Patients with severe left ventricular outflow tract obstruction may become profoundly hypotensive following ACEI administration, and therefore severe aortic stenosis is an absolute contraindication. Significant renal impairment occurs predominantly in patients with renovascular disease and particularly in those with severe bilateral renal artery stenosis. This is due to a combination of the reduction in systemic BP and the inhibition of AII-mediated renal efferent arteriolar vasoconstriction. ACEIs can also affect the renal function of patients with significant renal parenchymal disease, although these drugs play an important role in the treatment of patients with impaired renal function [96]. Pre-existing renal impairment also increases the risk of hyperkalaemia. Cough is also a common reason for ACEI intolerance. In the HOPE study, $7 \%$ of patients withdrew due to ACE induced cough [94]. By contrast, angioedema is potentially fatal but rare and not always life threatening, with a reported incidence of approximately 0.4 $\%$, although the true incidence is higher since ACEI intolerant patients was excluded prior to randomization [94]). ACEIs are teratogenic and therefore contraindicated in pregnancy. This is a major issue if their use is contemplated in young women.

ACEIs have several important interactions with other drugs.
Co-administration with NSAIDs increases the likelihood of renal impairment and hyperkalaemia. Concomitant potassium supplements and potassium-sparing diuretics will also potentiate the risk of hyperkalemia [90]. ACE inhibition is more effective in patients with high levels of renin activity, and it follows that hypotension is more likely in patients with pre-existing hypotension, hypovolemia or hyponatremia. Thus, diuretics may intensify the BP lowering effects of ACEIs, as may the concomitant use of any negative inotropic agents (eg beta-blockers, calcium- channel blockers). In patients with severe impairment of left ventricular function the use of ACEIs may be precluded. Conversely, this interaction is helpful in the setting of hypertension. It is this rationale that has led to the development of combination ACEI/diuretic and ACEI/calcium-channel blocker formulations [97].

\section{Angiotensin type 1 receptor blockers (ARBs)}

ARBs are nonpeptide compounds that specifically block the binding of AII to the ATR1 [13]. They do not interact with ATR2s. The block of feedback inhibition of renin release activates the RAAS cascade and AII production. The AII generated may interact with ATR2s, an effect that may result in vasodilatation and further BP reduction and, according to some recent experimental evidence, may result in inhibition of angiotensin and revascularization [38]. The ARBs are highly effective and well-tolerated antihypertensive medications, and recent clinical trials have shown that these agents have renoprotective effects beyond lowering BP [98]. There are currently 7 ARBs available: candesartan, eprosartan, irbesartan, losartan, olmesartan, telmisartan, and valsartan. All share similar modes of action, including indirect arterial vasodilatation by blockade at the AT1R, vasodilatory contribution from AT2R stimulation, decreased sympathetic nervous system activity, possibly lowered Aldo concentrations, decrease in vasoconstrictor substances such as endothelin and/or improvement in endothelial dysfunction, and a mild natriuretic response [99]. Pharmacologic differences exist for the various ARBs; however, differences in antihypertensive potency and duration of action of the ARBs have been inconsistently reported [100]. In fact there is no data that clearly and convincingly separate one ARBs from the other based on differing mechanisms of action and pharmacologic differences such as bioavailability, protein binding, and half-life [99]. Bioavailability has been touted as a way to distinguish ARBs from another. Three of the ARBs are administered in a prodrug form-losartan, candesartan cilexitil, and olmesartan medoxomil-although, technically speaking, losartan is an active compound, albeit one ultimately converted to its more potent metabolite. Although there is a considerable degree of variance in bioavailability between individual ARBs, this pharmacologic parameter has a limited effect on drug response and cannot be viewed in isolation from the other core pharmacologic features of an ARB [101]. The protein binding of all ARBs is typically well in excess of $90 \%$. Irbesartan is the exception to this in that it has a plasma-free fraction of approximately $10 \%$. In general, none of the ARBs bind to partitions in red blood cells in a meaningful fashion. Furthermore, the extent of protein binding for the ARBs remains constant over a wide concentration range. Heavily protein-bound drugs generally have a small volume of distribution; however, protein binding is not always an accurate predictor of volume of distribution. While telmisartan and losartan have similar protein binding, telmisartan has a lesser affinity for the albumin receptor and therein a much larger volume of distribution [99]. The half-life of a compound is a pure pharmacokinetic term, which often poorly correlates with a compound's duration of effect. The discrepancy between the pharmacokinetic and pharmacodynamic half-life of a compound comes from the fact that a component of 
drug action derives from extravascular effects. Because of the inability to sample at these extravascular sites of action, the more meaningful tissue-based half-life cannot be determined. This is particularly the case for the ARBs, since AT1Rs are found in multiple extravascular locations and blocking these receptors, may, in an as-of-yet undefined fashion, influence the manner in which BP is reduced [101]. With the above in mind, the pharmacokinetic half-life of an ARB will roughly approximate its duration of effect as long as the plasma concentration of an ARB remains above the threshold for a BP-lowering effect. Several of the ARBs, such as candesartan, olmesartan, telmisartan, and irbesartan, are considered once-daily compounds in pharmacokinetic terms. The true impact of pharmacologic half-life for these compounds probably lies more so in the fact that the drug is available for a longer period and thereby binds to additional AT1Rs as they are formed during the latter portion of a dosing interval.

The indications for the several ARBs on the market are mostly BP driven. Differentiation of one ARB from the other requires that drugs be studied in the same patient types and therein variable responses sought. Without a homogeneous population, heterogeneity weights results toward more non-responders, which is both a phenotypically and genotypically difficult state to characterize. From a BP point of view, for either an ARB or an ACEI, a practical approach is to go to the package insert, which has a low-end and high-end dose for every drug. ARBs are fairly equivalent at their low-end and high-end doses, with the probable exception of losartan. If a patient is a responder to an $\mathrm{ARB}$, it is evident even at low-end doses. If a patient is a nonresponder to an ARB, they remain so even as the drug's dose is increased and/or a within-class switch is made [102]. Thus, in those studies where BP is not the most important determinant of response, the results are then more so a matter of the specific dosing with a particular compound. A pertinent example of this is found in the Valsartan Heart Failure Trial (Val-HeFT) wherein valsartan was administered at a maximum dose of $160 \mathrm{mg}$ twice daily [103]. When an ARB is administered twice daily for a non-BP outcome it becomes quite difficult to establish "equivalent" doses for other ARBs. The Losartan Heart Failure Survival Study (ELITE II) was conducted to compare the effects of losartan (50 mg once daily) and the ACEI captopril (50 mg 3 times daily) on survival in elderly patients with HF. The primary end point was all-cause mortality and the secondary end point was sudden death or resuscitated arrest. The study did not have a superior outcome with losartan; however, losartan was administered only once daily at a low-end dose and this was believed by many to be the basis for the comparable response between captopril and losartan [104]. These findings could be interpreted to represent an intraclass difference when in point-of-fact they represent inadequate dosing. This is another of the vagaries in attempting to unravel the issue of class effect for individual ARBs [101]. Recently, another possible beneficial effect of telmisartan on metabolic syndrome has been described. In fact, this ARB can function as a partial agonist of peroxisome proliferator-activated receptor [105]. The clinical significance of these differences among members of the class remains to be determined in outcome trials.

The reported side effect profiles of ARBs are similar to placebo in hypertension and HF. ARBs can thus be characterized as having a wide therapeutic window, with virtually no dose-dependent side effects. This finding, taken together with some data of improved outcomes at higher doses, suggests higher doses might provide better target organ protection. A possible exception to the benefits of ARBs in HF is their potential lack of safety in combination with $\beta$ blockers. In ELITE II, mortality was higher with the $\beta$ blocker losartan combination than with $\beta$ blocker-captopril [104] and in Val-HeFT, valsartan caused higher mortality than placebo in individuals receiving both ACE inhibitors and $\beta$ blockers [103]. However, in those studies exploring the efficacy of such combinations in order to control BP in patients with type 2 diabetes mellitus did not showed any increased risk of mortality [106]. Furthermore potential mechanisms explaining the increased mortality of the $\beta$ blocker-ARB combination are not known at this time, however they can be used together in patients with coronary artery disease or HF when outcome improvement is the primary objective [97].

\section{Role of ACEIs and ARBs in renoprotection}

It only has passed two decades since the initial laboratory experiments that showed the effect of RAAS blockade on glomerular permeability to the resent clinical studies where ACEIs and ARBs have shown their efficacy as therapeutic agents for slowing renal disease progression. Renoprotection with both drugs have invariably shown that their renoprotective benefit is mainly explained by their specific antiptoteinuric effects. This is consistent with the view that proteins, once leaked through the glomerular barrier, act as mediators of ongoing renal fibrosis [107]. Thus in patients with renal disease reducing albuminuria remain an important strategy for renal and cardiovascular protection. The experimental demonstration that the blockade of AII with an ACEI slowed the progressive loss of renal in a number of animal models or renal diseases, including diabetic nephropathy, offered the opportunity, for the first time, to devise a treatment strategy that was not limited to passively accompany patients to their destiny of dialysis, but was aimed to preserve renal function as long as possible $[108,109]$. Based in these circumstances and several experimental and clinical studies emerged the concept of renoprotection [110]. The development of a new class of the drugs, the ARBs has offered another opportunity to further improve the renoprotection. In fact the near complete abolition of AII activity is instrumental to achieve full renal protection. Thus the combination of the two drugs, an ACEI and an ARB, in an experimental model of chronic nephropathies was associated with greater reduction of proteinuria and a trend toward less renal injury than with each drug alone [111]. Until now, it has considered as the main goal of current treatments the arrest of renal disease progression, however, the kidney has a great potential of regeneration after injury. Experimental evidence is accumulating that there is potential for regression of renal scarring, as shown in a paper by Fogo, in which the mechanisms of regeneration are reviewed [112]. Of note, the potential antifibrotic role of drugs that block the RAAS system is underlined [113]. Despite many uncertainties and as yet unknown factors, regression of human kidney disease now represents a realistic potential clinical target. A relevant body of evidence, based in experimental and clinical studies, indicates that, by mechanism yet to be define, the glomerular capillary network can sometimes undergo a process of both structural and functional regeneration [114]. In relation to the regression phenomena in chronic nephropathies, there are three main issues open for investigation. First, it is still a matter of controversy whether regression can be achieved in a consistent percentage of patients and to what extent $[113,115]$. Second, there are some disparities between the extent of the observed regression of structural changes and its translation into effective improvement of kidney function. At present, we know that controlling proteinuria seems to be a relevant factor for the progression of the disease [116]. The third refers to that the regression of renal lesions can be achieved in all progressive forms of glomerulopathies, or will only some types of renal diseases respond [117]).

Recent clinical data showed that for patients at low renal risk and with low levels of albuminuria, RAAS inhibition might not offer any renal benefit [118]. In these patients agents that blocks RAAS should be 
used sparingly, doses should be titrated to individual needs and kidney function should be monitored closely. Although RAAS blockade is thought to have major nephroprotective properties in individuals with diabetes, attention should be devoted to the identification of patient subgroups that can profit most from this treatment regimen. In addition, results from the RASS study, performed in type 1 diabetes mellitus patient with normal BP and normoalbuminuria, strongly suggest that trials of RAAS blockade in patients with diabetes and a low CV burden require a much longer follow-up period than is usually assumed [119]. Such trials of longer duration are needed to establish whether such a treatment regimen offers clinical benefit in the primary prevention of both microvascular and CV complications, which remain the major cause of morbidity and mortality in patients with diabetes [120].

\section{Role of ACEIs and ARBs in cardiovascular proteccion}

As already mentioned there is evidence that RAAS activation is involved in the process of injury and remodeling of $\mathrm{CV}$ tissues. This suggests that treatments suppressing the RAAS might exert an additional specific cardioprotective effect compared to non-RAAS inhibiting antihypertensive medications. In the general population as well as in specific high-risk patient subgroups ACEIs are the antihypertensive agents with the best risk-benefit profile. They have been consistently reported to reduce CV mortality, myocardial infarction, stroke, renal impairment, and even diabetes in patients with arterial hypertension and/or other CV risk factors [121]. They also improve survival of patients with HF or left ventricular dysfunction, previous myocardial infarction, stroke, or transient ischemic attack or with peripheral vascular disease and diabetes [92,94,122]. A recent meta-analysis of 33,500 patients included in six randomized clinical trials [123] and a pooled analysis of the Heart Outcomes Prevention Evaluation (HOPE), the European Trial on Reduction of Cardiac Events with Perindopril in Stable Coronary Artery Disease (EUROPA), and the Prevention of Events with Angiotensin-Converting-Enzyme Inhibition (PEACE) trials [124] showed that ACEIs reduce mortality and CV events also in patients with coronary artery disease but preserved left ventricular function.

It is accepted that ACEIs are the cornerstone of HF therapy and improve survival in patients with $\mathrm{HF}$ and left ventricular dysfunction. Studies have shown the efficacy of ACEIs in all symptomatic classes of systolic HF patients including those patients with some degree of renal dysfunction. Thus, a meta-analysis of five randomized trials of ACEI therapy in patients with HF showed that although the proportion of patients who developed renal dysfunction was higher in the ACEI groups than in the placebo groups, drug discontinuation was required in only a small percentage of patients, and renal function returned to baseline in most patients even without dose adjustment [92]. A retrospective analysis of the studies of left ventricular dysfunction (SOLVD) has shown that the use of ACEIs was associated with a reduced risk of mortality, even at moderately and severely depressed levels of GFR, and did not have an adverse impact on kidney function [125]. Therefore, in patients with chronic HF (CHF), mild-to-moderate renal insufficiency should not be viewed as a contraindication to ACEI therapy, and a mild and nonprogressive worsening of renal function during initiation of therapy should not be considered an indication to discontinue treatment, as the drug may offer the dual benefit of reducing disease progression in both the heart and the kidney [126]. In patients with moderate or severe renal insufficiency, therapy with low doses of ACEIs should be initiated and the dose should be increased gradually with careful monitoring of renal function and serum electrolytes. When the initiation of ACEI therapy leads to an increase in serum creatinine levels of more than 30\% above baseline, several strategies have been suggested [127]. First, ACEIs should be discontinued, and the patients should be evaluated for conditions causing renal hypoperfusion in which the use of ACEIs may result in acute renal failure, such as excessive depletion of circulating volume due to intensive diuretic treatment, concurrent administration of vasoconstrictor agents (eg, nonsteroidal anti-inflammatory drugsNSAIDs) and severe bilateral renal artery stenosis. Unless renal vascular disease is present, therapy with an ACEI can be reinstituted after correction of the underlying cause of reduced renal perfusion [128]. The risk of hyperkalemia associated with the use of ACEIs in patients with HF and renal dysfunction is also a source of concern. Several measures may be used to minimize the risk of hyperkalemia in such patients, including discontinuation of drugs known to interfere with renal potassium excretion (e.g. NSAIDs, including cyclooxygenase-2 inhibitors), administration of a low potassium diet, as well as sodium bicarbonate in patients with metabolic acidosis [129]. A potassium level of $\geq 5.5 \mathrm{mEq} / \mathrm{L}$ should prompt a reduction in the ACEI dose. Regarding cardioprotective effects of ARBs in HF, there is evidence that AII is produced in the myocardium through alternative pathways independent of ACE that involve enzymes such as chymase, which are not blocked by ACEI. An augmented activity of these local pathways may lead to increased production of AII in patients with HF, and AII is a major adverse influence of cardiac remodeling and dysfunction. The ARBs have been compared with ACEIs regarding their effect on survival and renal complications in HF patients. Although the ELITE (Evaluation of Losartan in the Elderly) trial [130] found a mortality benefit in favor of losartan compared with captopril, the larger ELITE-2 trial that followed did not confirm this finding; rather, it found no difference [104]. Unfortunately, patients who experience hyperkalemia or worsened renal function while taking ACEIs are likely to have the same complications with an ARB [131]. Therefore, at present there are two settings in which AII receptor blockers might be used in HF: as an alternative in patients intolerant of ACEIs due to cough, and in combination with ACEIs in patients who remain severely symptomatic on conventional therapy [132].

An important area of interest corresponds to the role of atrial fibrillation (AF) as a factor on $\mathrm{CV}$ risk. Patients with $\mathrm{AF}$ have a mortality risk that is twofold than those without [133]. Left ventricular hypertrophy and dilation are invariably associated with reduced diastolic left ventricular compliance and secondary increase in left atrial pressure and size. These changes contribute to structural and electrical remodeling of the atria that eventually lead to an increased risk of AF. It has been described that those patients with a higher prevalence of $\mathrm{CV}$ risk showed an increased atrial expression of ACE and the AT1R, in addition to activation of AII-dependent downstream signalling pathways involved in fibrogenesis, that have been found to affect electrophysiological properties of the myocardium and the pulmonary veins [134]. Recent data suggest that AT1Rs are located in close proximity to potassium channels within the membrane and that AII inhibits outward potassium currents that are involved in the pathophysiology of AF [135]. On the basis of the above findings, RAAS blockade might be a rational approach for the prevention and treatment of AF. The use of ACEIs was associated with less atrial fibrosis [136], and ARB therapy improved electrical remodeling [137]. A recent meta-analysis of 23 randomized controlled trials including 87,048 patients showed that RAAS inhibition is effective in the primary and secondary prevention of AF [138]. Moreover, in the context of primary prevention, patients with LVH and/or HF benefit most from RAAS 
inhibition. In secondary prevention after cardioversion of persistent AF or medical therapy for paroxysmal AF, RAAS inhibition is overall beneficial.

\section{Blockade of the RAAS with ACEIs and ARBs is only Partial}

As previously mentioned in patients with kidney and CVD, ACEIs have beneficial effects over and above their antihypertensive actions. Blocking the generation of AII also reduces the proinflammatory, profibrotic and oxidative effects of this peptide. However, because several alternative enzymes and pathways exist in the RAAS, the capability of ACEIs to suppress AII generation may be limited [13]. The fact that therapy with ACEIs alone may only achieve a partial blockade of AII production led to the development of agents that directly inhibit the effect of AII at its ATR1. Since there became available, ARBs have shown in prospective, randomized studies to attenuate the progression of renal disease in patients with type 1 and type 2 diabetes mellitus and advanced diabetic nephropathy [139]. However, as with ACEIs, the capability of ARBs to inhibit the activity of the RAAS is limited by the complexity of this system. Due to a negative feedback mechanism AII suppresses renal renin activity, and during therapy with ACEIs or ARBs this mechanism is attenuated. Consequently, plasma renin activity (PRA) is substantially increased in patients taking these drugs. In patients receiving ARBs as monotherapy, not only does PRA increase, but AII levels may also rise since ACE activity remains intact. This phenomenon can be termed 'angiotensin breakthrough'. The increased levels of AII that occur with ARB treatment could potentially override ARB-mediated blockade of the ATR1. By contrast, activation of the ATR2 could have vasodilatory and antiproliferative effects. In the same way, the rise in PRA that accompanies therapy with ACEIs may attenuate inhibition of the RAAS. Moreover, AII is cleaved to A(17) by ACE2 and as a result of treatment with ACEIs and ARBs, the levels of A(1-7) increase and counteract the effects of ATR1 receptor activation by AII [63].

Given the limitations of monotherapy with either ACEIs or ARBs, combination therapy with drugs of both classes is frequently used to improve inhibition of the RAAS [140]. As an example, in patients with congestive HF who were treated with ACEIs, the addition of an ARB was beneficial despite being associated with an increased incidence of hypotension, diminished renal function and hyperkalemia [141]. However, the Ongoing Telmisartan Alone and in Combination with Ramipril Global End Point Trial (ONTARGET), showed that patients with diabetes or at a high risk of $\mathrm{CV}$ complications had a modest decrease in renal function while receiving combination therapy with an ACEI and an ARB [142]. Besides an increase of PRA, ACEI therapy also results in an initial decrease in plasma Aldo level. However, in some patients treated with ACEIs, plasma Aldo concentrations return to normal levels over a variable period of weeks or months [143]. This phenomenon referred as "Aldo breakthrough" has also been described in patients who report chronic use of ACEIs or ARBs and has been related with worse clinical outcomes. The "Aldo breakthrough" observed with ARB treatment may be related to increased AII levels. Whether the addition of a MCR antagonist would have beneficial effects in patients who experience this phenomenon remains unknown; however, large trials using non-natriuretic doses of MCR antagonists showed an improved survival in patients with either severe CHF or congestive HF secondary to acute myocardial infarction [51]. These data suggest that the downstream effects of Aldo-increased inflammation, fibrosis, apoptosis, and oxidative injury-could potentially be blocked by concurrent therapy with aldosterone-receptor antagonists (ARAs) [144].

\section{Vasopeptidase inhibitors (VPIs)}

VPIs are a new class of CV drugs that have the novel action of simultaneously inhibiting ACE and NEP, which is ordinarily responsible for the degradation of natriuretic peptides or atriopeptins [145]. Atriopeptins are potent endogenous vasodilators whose actions are similar in many respects to BK; both hormones have short plasma half-lives and stimulate the NO-cyclic guanosine monophosphate vasodilator cascade in VSM [146]. There are three major atriopeptin isoforms synthesized in the heart: atrial natriuretic peptide (ANP), brain natriuretic peptide (BNP), and vascular natriuretic peptide. All are vasodilators that also cause natriuresis. ANP and BNP inhibit a variety of vasoconstrictors such as endothelin, cause inhibition of sympathetic nervous and RAAS activity, and blunt cell proliferation and hypertrophy. All three atriopeptins are removed from the circulation primarily as a result of enzymatic degradation by NEP and to a lesser extent through clearance by the natriuretic clearance receptor [147]. The natriuretic peptide system can be viewed as the endogenous inhibitor of the RAAS. Simultaneous inhibition of the RAAS and the NEP system by the VPIs results in vasodilation, natriuresis and diuresis, and decreases peripheral vascular resistance and BP to a greater extent than ACEI alone. Therefore, in theory, inhibition of the RAAS combined with potentiation of natriuretic peptides/kinins should lead to improved CV haemodynamics and sodium/water balance [148]. In experimental studies a new VPI, AVE7688, showed a superior action on renoprotection than enalapril in progressive renal injury, based in the correction of the altered balance between vasoconstrictor/vasodilator mediators in the kidney [149]. Moreover, the structural similarities in the active sites of both NEP and ACE had made the simultaneous inhibition of these two enzymes an attractive target for drug development. A number of such dual VPIs entered preclinical and clinical development in the 1990s. These agents, which vary in their inhibitory activity for ACE and NEP, include omapatrilat, SA 7060, MDL 100240, MDL 10017, fasidotril, sampatrilat, alatriopril, CGS 30440 and S 21402 [145]. Of the dual VPI, omapatrilat has been the most extensively studied in clinical trials. In early studies with this compound, it was shown to be superior to ACEIs as an antihypertensive agent and in the treatment of heart failure [150]. Although initially attributed to benefits beyond ACE inhibition, omapatrilat was shown to be a weak diuretic, with thiazide diuretics providing additional BP reduction. These findings led to the conclusion that the efficacy of omapatrilat in hypertension and HF may be attributable in large part to the potentiation of kinins. Despite the immense enthusiasm generated by initial studies, larger definitive studies were ultimately unsuccessful. Also, the high incidence of angioedema, when compared to enalapril reported in subjects treated with omapatrilat in the Omapatrilat Cardiovascular Treatment Assessment Versus Enalapril (OCTAVE) trial, might limit its use. Whether this adverse-effect profile is shared by other members of the VPI class that are under development remains to be determined [151]. In OCTAVE, omapatrilat use was associated with a significantly higher overall incidence of nonfatal angioedema compared to enalapril, a problem that was amplified in African Americans. The mechanisms for these differences remain unknown but are presumed to be related to abnormal bradykinin metabolism [152]. Why the ACE-NEP inhibitor combination is superior in potency to ACEIs alone is an interesting phenomenon given that "pure" NEP inhibitors cause no marked effects on BP, even in the setting of HF [153]. The endothelium and the neurohumoral system play a key role in modulating both vascular tone and structure by producing vasoactive substances, and in the modulation of blood cell adhesion. Although the neurohormonal systems are essential in vascular homeostasis, 
they become maladaptive in conditions such as hypertension, diabetes and HF. The clinical success of RAAS blockade by ACEI and the sympathetic nerve system by beta-blockers demonstrates the importance of neurohumoral blockade. In this sense, VIPs represent a new and attractive therapeutic strategy for the treatment of CVD, although if this drugs add an incremental benefit over already proven therapy, with an acceptable side-effect profile is questionable [150]. However, in the complex equilibrium among RAAS, sympathetic nervous and natriuretic peptide systems, omapatrilat, would offer some theorical advantages, by blocking a pro-fibrotic mechanism and stimulating an anti-fibrotic phenomenon [154]. Therefore, despite the immense theoretical appeal of blocking both ACE and NEP, the limited incremental benefit of this drug class along with the greater possibility of angioedema has limited its potential utility. However, the fact that newer VPI, such as M100240 (Sanofi Aventis, Paris, France) are currently entering early phase human trials suggests that this class of drug may still have a future in the clinic. Again, the global RAAS blockade perspective would include the combined inhibition of ACE and NEP as a new promising approach to treat patients with hypertension, atheroesclerosis or HF.

\section{Direct renin inhibitors (DRIs)}

Renin long has been recognized as the preferred, logical target for RAAS blockade because it corresponds to the first, highly regulated and rate-limiting step of the system. Renin also has a remarkably high specificity for only one known substrate, angiotensinogen contrary to ACE. The clinical development of the first transition-state synthetic analogs capable of inhibiting renin has faced a number of technical problems. The oral administration of these renin inhibitors in human beings (ie, remikiren and zankiren) did not meet all the necessary criteria for these drugs to be considered clinically useful. Molecular modeling and determination of the structure of the active site of renin have led to the identification of new renin inhibitors (DRIs) [155]. The first representative of this class of nonpeptide drugs is aliskiren, a potent hydrophilic transition-state mimetic alkane carboxamide renin inhibitor with a very high binding affinity for renin, resulting in selectivity for this enzyme [156]. It is a potent competitive renin inhibitor that binds strongly to renin and is highly specific for human renin. As with ACEIs and ARBs, the administration of a DRI increases circulating and intrarenal enzyme (renin) levels by interrupting the AII-renin negative feedback loop. However, with a renin inhibitor, the catalytic activity of the renin molecules newly released from the kidney is inhibited completely throughout the day, resulting in very low circulating levels of AI, AII, and other AI-derived peptides, thereby rendering the RAAS quiescent. In contrast, the renin molecules newly released from the kidney remain enzymatically active after administration of an ARB or an ACEI, resulting in high circulating levels of AI, with variable levels of AII depending on the drug used. This counter-regulatory renin release could offset the pharmacologic inhibition of the RAAS at the end of each dosing interval, when the amount of competitive inhibitor or antagonist on the ACE or AT1R is decreasing [82]. Aliskiren does not affect cytochrome P450, so this agent has few drug interactions and its dose need not be adjusted even in patients with advanced CKD due that is eliminated by the hepatobiliary route without being metabolized. This agent has a long half-life, which might enable improved $24 \mathrm{~h} \mathrm{BP}$ control, particularly in obese patients with diabetes mellitus and in individuals with CKD whose BP does not show a nocturnal dip. A study of diabetic patients on maximum ARB doses with well-controlled $\mathrm{BP}$ and estimated glomerular filtration rates less than $70 \mathrm{ml} / \mathrm{min} / 1.73 \mathrm{~m} 2$ examined the effects of adding aliskiren to this treatment, versus adding placebo (AVOID study) [157]. This study showed that the combination of ARB and aliskiren substantially reduced the urinary albumin excretion and this effect seemed to be independent of BP control [158]. Also the incidence of hyperkalemia was similar between placebo and DRI groups. Aliskiren treatment seems to have an AII-dependent vasodilatatory effect on the efferent arteriole in the glomerulus that causes an increase in renal plasma flow and a drop in filtration fraction that exceeds the effect seen previously with ACEIs and ARBs [159]. In addition, aliskiren inhibits the intrarenal RAAS even several days after cessation of treatment [160]. Thus, it has been previously demonstrated a synergistic response to combination treatment with aliskiren and irbesartan, as measured by a 12 -fold increase in plasma renin concentration, pointing to increased intrarenal RAAS blockade [161]. There are several trials analyzing the effects of DRIs on CVD or renal diseases. Aliskiren reduces PRA and neutralizes HCTZ -induced RAAS activation. The reduction of PRA is important because PRA is related and CHF [162]. Oncedaily administration of the drug leads to greater than 24-h activity and its prolonged blocking effects on the kidneys are the basis for its reno-protectivity. Aliskiren has demonstrated favorable effects on vascular inflammation, remodeling, and neurohumoral mediators of various forms of cardiovascular complications, including CHF and proteinuria in diabetic patients. The neurohumoral effects of aliskiren in comparison to ramipril and placebo has been studied in a group of 27 patients (aged $>50$ years) with symptomatic CHF (NYHA class II-IV, ejection fraction $[\mathrm{EF}]<35 \%$ ) during a period of 5 weeks [163]. Aliskiren significantly suppressed the BNP values more than ramipril in short-term treatment. Also, a 4-week randomized double-blind study performed in 236 mild-to-moderate hypertensive patients showed that PRA was reduced from baseline values between $55 \%$ to $83 \%$ with increased doses of aliskiren (contrasting with a $110 \%$ rise in PRA with losartan). In this study, the authors founded a comparable reduction $(-60 \%)$ in PRA with aliskiren in patients with CHF (compared with a $165 \%$ increasing with ramipril). PRA was suppressed by aliskiren, but it did not change with placebo; even if it increased with ramipril as expected, this increase occurred either in the first week or in the fifth one [164]. The Aliskiren in Left Ventricular Hypertrophy (ALLAY) study showed that aliskiren was as effective as losartan in reducing left ventricular mass (LVM), in 465 overweight (BMI >25), hypertensive patients randomized to receive aliskiren $300 \mathrm{mg}$, losartan $100 \mathrm{mg}$, or their combination daily for 9 months [165]. Aliskiren was as effective as losartan in promoting LVM regression. Reduction in LVM with the combination of aliskiren plus losartan was not significantly different from that with losartan monotherapy, independent of BP. Besides other trials, ATMOSPHERE (Aliskiren Trial to Minimise OutcomeS in Patients with HEart FailurE), will examine the potential clinical benefit of aliskiren in addition to other RAAS blocking agents as well as it will compare aliskiren head-to-head to ACEI therapy. This study should answer key questions regarding the clinical utility of DRI in CHF settings and, depending on the mechanistic substudies that have to be performed, may also investigate how these agents exert any observed benefits. Further to this, aliskiren will also be investigated in the ASTRONAUT (Aliskiren Trial on Acute Heart Failure Outcomes), which will evaluate whether an early therapy with aliskiren delays cardiovascular death and CHF rehospitalization within 6 months and posthospitalization for episodes of acute decompensated CHF [166].

The ongoing Aliskiren Trial in Type 2 Diabetes Using Cardiorenal End Points (ALTITUDE) trial is expected to provide definitive outcomes data on the effects of aliskiren in patients with type 2 diabetes on renal and cardiovascular morbidity and mortality [167]. This study will determine whether a dual RAAS blockade with aliskiren 
in combination with an ACEI or ARB will reduce major morbidity and mortality in a broad range of high-risk patients with type 2 diabetes. No published data have specifically examined the effect of adding a MCRs antagonist to DRI therapy. The Aliskiren Observation of Heart Failure Treatment (ALOFT) study investigated the effect of this agent in 302 patients with well-controlled hypertension and symptomatic congestive HF (class II-IV) who were on standard HF treatment ( $\beta$-blocker, ACEI or ARB) with or without aldosterone antagonists [168]. Finally, two ongoing trials, Aliskiren in VIsceral obesity AT risk patients Outcomes Research (AVIATOR) and Aliskiren Trial in Type 2 Diabetic nephropathy (ALTITUDE), will assess cardiovascular events and diabetic complications with aliskiren; the results will be available between 2011 and 2013.

\section{Selective aldosterone receptor antagonists (ARAs)}

The hormone Aldo has been recognized as a major independent adverse hormone in the pathogenesis and progression of a number of major cardiovascular disease states, including essential hypertension [169]. Also plasma Aldo levels have been correlated with alterations in kidney function in CKD suggesting an association between kidney dysfunction and mineralocorticoid receptors (MR) activation [170]. Patients with a heavy proteinuria have increased renal expression of MR and increased plasma Aldo levels that were correlated with the severity of renal biopsy findings [171]. Thus Aldo has been a well-known target for therapeutic intervention for many decades. As previously mentioned, the importance of RAAS blockade for slowing the progression to ESRD is well recognized, however the effects of MR antagonists (MRAs) on the progression of CKD are less well described than the effects of ACEIs and ARBs. Spironolactone a selective ARAs has been approved in the treatment of mineralocorticoid hypertension, ascites associated with portal hypertension and CHF. It has been widely used for the treatment of essential hypertension. However, this agent has been limited by its non-specificity for MR, including anti-androgenic and pro-estrogenic actions. On this basis, a more highly selective agent for the MR was developed by replacing the 17-alpha-thoacetyl group with a carbomethoxy group, eplerenone [172]. Several studies have clearly shown the beneficial impact on outcome of MRAs in HF as RALES [50], EPHESUS [173] and most recently, the EMPHASIS-HF [174]. Eplerenone has been studied in a large program exploring the potential benefits of the agent as monotherapy and add-on therapy in patients with essential hypertension, both undifferentiated and in those with low renin/high Aldo plasma levels [172]. To date, a number of doubleblind, randomized clinical trials have contributed to the database for the efficacy and safety of eplerenone in systemic hypertension. The effects of eplerenone on LVH and renal function associated with mild to moderate hypertension were assessed in a 9-month study of patients who received either eplerenone, enalapril or the combination [175]. Although the BP effects were similar, mean reductions in left ventricular mass and in the urinary albumin to creatinine ratio were higher in the combination group. However, studies of the effects of MRAs on the progression of CKD are limited, without any outcome studies examining loss of kidney function, progression to ESRD, or CV death as the primary outcome [54]. The use of MRAs in CKD is suggested by Aldo 'breakthrough' and is associated with increased proteinuria [143] or a faster decline in kidney function [176].

A recent meta-analysis of 11 controlled and randomized trials compared the effect of a MRAs in patients with CKD, albuminuria, or proteinuria due to diabetic and nondiabetic nephropathy, showed that spironolactone significantly decreased proteinuria when added to ACEI and/or ARB treatment without any change in renal function, but with a decrease in systemic BP [177]. The use of MRAs in proteinuric patients with CKD was first proposed by Chrysostomou et al. [178]. Initial reports and more recent analysis describe decreased BP after MRAs [177]. Other studies showed reduction in proteinuria independent of effects on BP at the doses used [59]. Whether part of the beneficial effects of MR antagonism in CKD is independent of effects on BP is a point of continuing debate. In the case of patients with diabetes mellitus and persistent proteinuria the use of MRAs either alone or added on ACEIs treatment have shown an antiproteinuric effect [179]. The efficiency was correlated with the Aldo level before the initiation of the treatment, and after MRAs withdrawal, proteinuria reappeared [180]. Most of the studies performed in diabetic patients used spironolactone which decreased albuminuria, renal excretion of MCP-1, and activation of oxidative stress [181]. Only one study has been performed with eplerenone showing tolerability similar to spironolactone and an antiproteinuric effect after 3 months [182]. For non-diabetic patients with proteinuria the addition of MRAs on RAAS blockade has also demonstrated their effect in reducing proteinuria [183]. Spironolactone has also showed not only a decreased of proteinuria but a slowed the progression of CKD [58]. A large-scale prospective, placebo-controlled evaluation of eplerenone versus conventional agents in hypertensive patients with proteinuria is underway, and is referred to as the EVALUATE Trial [184]. The primary end point is reduction in urine albumin/creatinine ratio after 12 months of active drug treatment, with secondary outcomes that include reduction in BP, hyperkalemia, and slowing of progression of CKD.

The adverse effects in MRAs could be divided in ionic effects (hyperkalemia and salt depletion related to the diuretic effect) and antiandrogenic effects (gynecomastia, disorders of the menstrual cycle, and so on, related to the nonspecific androgen receptor blockade). The use of MRAs has not been recommended in CKD patients because of the concerns about hyperkalemia which often occurs when multiple RAAS blockers are used [185]. Hyperkalemia may limiting the beneficial effects of MRBs and RAAS blockade in patients with CKD due to its effect on aldosterone secretion and contribute to aldosterone breakthrough [186]. Potassium has long been recognized as an important stimulus for Aldo secretion [90]. Spironolactone and eplerenone seem to have different adverse event profiles, particularly the anti-androgenic effects. This difference is due to the lower selectivity for MR of spironolactone together to its effect as an antagonist for the androgenic receptor in contrast to eplerenone, which is relatively more MR specific [187].

\section{Dual Blockade of the RAAS: To Whom, When and How?}

RAAS blockade is a cornerstone of treatment in CKD and CVD [84]. In particular, ACEIs and ARBs have proven efficacy for intermediate parameters (systemic and glomerular hypertension, and proteinuria) as well as hard cardiovascular and renal endpoints.

The dual blockade strategy comes from the concept called "Aldo scape" [10] based on the finding that incomplete blockade of the RAAS with ACEI or ARB monotherapy can cause a lack of negative feedback from end-products of the RAAS producing a reactive increase in renin and consequent increases in AI and AII concentrations which overwhelm the pharmacological blockade. Dual blockade would therefore be useful based on the fact that it could provide more complete blockade of the RAAS by limiting the compensatory responses of AII, Aldo, renin or their effects, thus maximizing blockade of the cascade. This 'maximization approach', however, may induce adverse effects such as hyperkalemia, symptomatic hypotension, or hemodynamically 
mediated deterioration of renal function [188]. Taking into account these effects a different approach to dual blockade could be to combine lower doses of the individual drugs to obtain a more favorable balance between increased efficacy and adverse effects. However, there is continuing uncertainty about the balance of benefits and harms of dual RAAS blockade, both in terms of cardiovascular risk and progression of kidney disease [189].

In terms of CV protection, dual RAAS blockade might have modest benefit in patients at a high risk of CV disease (e.g. those with known impaired left ventricular systolic dysfunction), but this would need to be balanced against the risk of hyperkalaemia and acute-on-chronic renal failure [189]. Whether the observed benefits of RAAS blockade are only mediated by their BP-lowering effect or whether other effects also play a role remains controversial; there is some evidence that interruption of the RAAS provides more benefit than would simply be expected by the degree of BP reduction alone [190].

Recently, a large meta-analysis by Kunz et al. [89] was conducted to determine if combination therapy is superior to monotherapy, and if ACEIs and ARBs are equivalent in efficacy with regard to proteinuria. After analyzing forty nine studies these authors found that reduction in proteinuria was more intense when these two drugs where use in combination. However they also highlight the fact about the uncertainty concerning adverse effects and outcomes that are important to patients could limit the applicability of these findings to clinical practice.

The decision about whether to initiate dual RAAS blockade for an individual patient requires careful assessment of their risks of renal progression, of $\mathrm{CV}$ events and of acute complications of dual RAAS therapy. Until further results are available, it would seem prudent to reserve dual RAAS blockade for patients who are at an increased risk of renal progression, such as those with significant proteinuria or with evidence of deteriorating renal function despite monotherapy [189]. Additionally, as the CV risk increases, so does the potential for $\mathrm{CV}$ benefit that may lower the threshold for the introduction of dual RAAS blockade. Further adequately sized trials in patients with progressive kidney disease with meaningful clinical endpoints are required to provide robust answers for clinicians and patients.

\section{The Case of Hypertension and Congestive HF}

There is convincing evidence that dual RAAS blockade with ACEI and $\mathrm{ARB}$ is valuable in reducing CV events in select populations. In patients with essential hypertension several studies has showed that dual blockade with ACEI/ARB is more effective than monotherapy, but also has more side effects, including hyperkalemia. However in those studies where maximal doses or longer-acting ACEI were used, there was no additional reduction in BP with dual RAAS blockade [191]. Whether any of the dual RAAS blockade combinations has a beneficial effect on hard CV endpoints in uncomplicated hypertension has not been investigated so far. Hence, dual RAAS blockade is not preferred over other drug combinations in these patients [10]. Other strategies including Aldo antagonists as alternative therapy for a better RAAS blockade has shown some benefits. Adding MRAs on top of ACEI or ARB resulted in a larger antihypertensive effect, at the expense, however, of hyperkalemia and gynecomastia [192]. Also, in hypertensive patients dual blockade including the DRI, aliskiren, combined with ACEI or ARB was more effective than monotherapy with one of the three drugs [193]. Diarrhea, and not hyperkalemia, appears to be the main side effect in uncomplicated hypertension

In patients with HF, a meta-analysis of seven trials of dual
RAAS blockade versus ACEI alone showed a decrease in hospital admissions for HF, but no effect on total mortality [194]. The CHARM study (Candesartan in Heart Failure Assessment of Morbidity and Mortality) [195] showed that the addition of candesartan to ACEI resulted in significant reductions in each of the primary outcomes, which included cardiovascular death and hospital admission for CHF. However, the rate of adverse events, such as symptomatic hypotension, hyperkalemia, and renal function decline, has proven higher than anticipated, thus limiting clinical application of dual blockade with ACEI/ARB in HF [196]. Accordingly, combined ACEI/ARB treatment is not advocated in the CVD population [10]. Also, dual blockade with MRA/ACEI or MRA/ARB in patients with CVD has shown favorable outcomes. In HF, including postmyocardial infarction left-ventricular dysfunction, MRA on top of ACEI or ARB more effectively reduced mortality and hospitalizations for HF than ACEI or ARB monotherapy [173]. Altogether, these findings have led to the recommendation for dual blockade with low-dose MRAs in carefully selected patients with left-ventricular dysfunction post myocardial infarction or HF [197] Data on dual blockade with DRI and ACEI or ARB in CVD are still sparse. Aliskiren added to ACEI or ARB in HF improved intermediate endpoints as circulating NT-proBNP and urinary aldosterone despite the absence of an effect on BP [168]. However, the effects of dual therapy with DRI on top of ACEI or ARB in patients with CVD disease remain to be verified in long-term large clinical trials.

\section{The Case of CKD}

The priorities in the management of $\mathrm{CKD}$ are to prevent cardiovascular events, retard progression, manage metabolic complications, and prepare patients for renal replacement therapy [189]. The current evidence suggests that dual RAAS blockade may be a treatment with significant benefits and risks. Therefore, understanding the baseline risk of the patient for $\mathrm{CV}$ and renal events is crucial.

In patients with CKD dual blockade with ACEI/ARB has been shown to reduce BP and proteinuria more effectively than either monotherapy, especially when baseline proteinuria was high $[140,89]$. However, evidence for a benefit of ACEI/ARB combination on hard endpoints in CKD is lacking. In general, it would be logical to assume that the potential benefits of dual blockade with ACEI/ARB depend on the specific risk profile of the population treated. The initiation of dual blockade is likely to cause an acute reduction in GFR due to reduction in intraglomerular pressure just as starting ACEI or ARB monotherapy does [126]. If the reduction in GFR is not progressive, however, it would be reasonable to continue such treatment, especially if it reduces BP or perhaps proteinuria. Close monitoring is also indicated if the patient is receiving other medications that may increase the risks of acuteon-chronic renal failure and/or hyperkalaemia (e.g. Aldo antagonists, non-steroidal anti-inflammatory drugs or beta-blockers). A subgroup analysis of the ONTARGET study, showed that dual blockade was harmful only in individuals with a low renal risk (i.e. without diabetes and hypertension, or without albuminuria), whereas in patients with albuminuria a trend towards a better renal outcome was observed [198]. Despite a beneficial effect on microalbuminuria, dual blockade was associated with a worse renal outcome, raising vigorous debate. Considering the patient selection in the ONTARGET study, it may be unwise for the moment to extrapolate these findings to CKD patients with overt proteinuria, when the benefit/risk ratio may be very different, considering the antiproteinuric potential of dual blockade. Recently it has been considered other strategies trying to evaluate the effects of greater blockade of the system. Thus triple blockade with MRA/ACEI/ ARB have also been studied in proteinuric CKD patients. This scheme 
of treatment reduced proteinuria to the same extent as MRA/ACEI, but to a greater extent than ACEI/ARB [59]. However, other studies have shown a superiority of MRB/ACEI/ARB over ACEI/ARB [199]. With triple blockade, more hyperkalemia and a larger renal function decline arose. Long-term effects on renal outcome, mortality, and safety, of different degrees of blockade with MRA in CKD patients remain to be determined. In relation to those strategies dual blockade with DRI on top of ACEI or ARB in patients with CKD there is very limited clinical evidence. In diabetic nephropathy, the combination of DRI/ $A R B$ reduced proteinuria more effectively than monotherapy ARB, independent of the effect on BP [157]. The incidence of hyperkalemia and adverse events were similar in both groups. Finally, we would like to propose that before considering dual or triple blockade involving different combinations more attention should be paid to gain optimal effect of single drug RAAS blockade. This implies individual dose titration and explicit correction of volume excess [200]. Whether combined ACEI/ARB results in better therapeutic effects than single RAAS blockade with volume correction measures is currently under study (DUAAAL study, Dutch Trial Register, NTR675) [10].

\section{The Relation between Vitamin D and RAAS: A Step forward Global Blockade of the System}

Vitamin D is typically viewed as a key player in the regulation of calcium and phosphate levels and the control of bone metabolism; however, growing evidence suggests that vitamin D deficiency may also have an important role in the progressive loss of renal function. Studies indicate that treatment with vitamin $\mathrm{D}$ analogues reduces proteinuria, suppresses the RAAS, and exerts anti-inflammatory and immunomodulatory effects [201]. In experimental animals Li et al. demonstrated that vitamin $\mathrm{D}$ is a potent negative endocrine regulator of the RAAS and acts as a suppressor of renin biosynthesis [202]. Vitamin D suppresses renin expression independently of its effect on calcium metabolism as well as independently of its effect on the volume- and salt-sensing mechanisms and the AII feedback regulation [202]. More recently, these authors also demonstrated that the combination of and ARBs plus paricalcitol (a vitamin D receptor agonist; VDRA) therapy abrogates progression of renal disease in streptozotocin-induced diabetes [203] and the mechanism of renal protection appears to be by protection of the podocyte and blockade of the TGF- $\beta$ system in the glomerulus. Furthermore, VDRAs have also anti-inflammatory effects so these pleiotropic effects render vitamin $\mathrm{D}$ a potentially interesting treatment modality for renoprotection in patients with CKD although the renoprotective mechanisms in humans remain to be discovered. One possibility is that VDRAs block the RAAS in tissues without affecting the endocrine system [201]. In fact at present there are four published studies on the renoprotection by VDRAs among patients with CKD not on dialysis [204-207]. In all of them, those patients that received treatment with either paricalcitol or calcitriol showed a reduction on their proteinuria and some inflammatory parameters (high-sensitivity C-reactive protein, serum TGF- $\beta$ level). More recently, the Selective Vitamin D Receptor Activator for Albuminuria Lowering (VITAL) study tests whether paricalcitol persistently reduces albuminuria in diabetic subjects already receiving inhibitors of the RAAS [208]. In this double-blind multicenter trial performed in type 2 diabetic nephropathy and albuminuria the addition of $2 \mu \mathrm{g} / \mathrm{day}$ paricalcitol to RAAS inhibition safely reduced residual albuminuria. At present vitamin $\mathrm{D}$ calls for at least maintaining adequate stores of vitamin $\mathrm{D}$ for bone health and perhaps cardiovascular, immunological, and renal health among patients with CKD. Although VDRAs reduce proteinuria, whether these agents can prolong the time to ESRD and should become the standard of care among patients with CKD remains to be answered by well-designed controlled clinical trials [209].

\section{RAAS and Inflammation: Clinical and Therapeuthical Implications}

Vascular inflammation plays a key role in the pathogenesis of atherosclerosis as well as of $\mathrm{CV}$ remodeling in hypertensive conditions. In recent years it is becoming increasingly accepted that those situations where CV complications are present as in CKD and diabetes, there is an state of chronic inflammation that is associated with oxidative stress, endothelial dysfunction, vascular calcification and wasting [210]. However, the reasons and mechanism for this inflammatory situation are complex and seems to be related to a combination of diverse factors that cause an altered immune balance [211].

As commented previously, the roles of AII go well beyond controlling circulatory homeostasis. Recently, a large number of experimental studies have shown that AII mediates several key events of the inflammatory processes [212]. Inflammation involves activation of the endothelium of blood vessels and expression of diverse endothelial cell selectins that dictate extravasation of specific leukocyte populations to the site of injury [213]. In the context of an inflammatory process, local activation of RAAS and AII synthesis both increased vascular permeability by promoting the expression and secretion of VEGF (vascular endothelial growth factor), and induced the expression of endothelial adhesive molecules including selectins (P- and L-selectin), vascular cell adhesion molecules-1 (VCAM-1), intercellular adhesion molecules-1 (ICAM-1) and their ligands, the integrins [214]. Moreover, AII also favours the recruitment of infiltrating inflammatory cells into tissues by stimulating the production of specific cytokine/chemokines. Thus in the aorta of spontaneously hypertensive rats, which bear elevated levels of AII, massive macrophage infiltration is accompanied by increased expression of monocyte chemoattractant MCP-1 and one of its receptors, the $\mathrm{C}-\mathrm{C}$ chemokine receptor CCR2. Modulation of MCP-1/CCR2 via ATR1 blockade reduces vessel inflammation in these rats [215]. In models of progressive nephropathies, interstitial accumulation of macrophages is accompanied by increased renal expression of MCP-1, and renoprotection afforded by the ACEI lisinopril limits interstitial inflammation and reduces MCP-1 expression [216]. The pro-inflammatory activity of AII is also mediated by activation of dendritic cells (DCs), highly specialized antigenpresenting cells responsible for inflammation defense and immune response [214]. In rats with subtotal renal ablation, blockade of AII synthesis/biological activity reduces local DC accumulation and attenuates tubulointerstitial damage [217]. The beneficial effect of AII blockers on tissue inflammation also relies on their ability to block AII-mediated activation of Toll-like receptors (TLRs). In vivo studies have shown protection against myocardial ischemia/reperfusion injury after ATR1 blockade through suppression of TLR-4 expression and reduction of cytokine release [218]. The pro-inflammatory effects of AII can also involve T cells. During inflammation, AII acts via its ATR1 to stimulate cytoskeletal rearrangements in T cells and to trigger the release of specific cytokines and chemokines that favour $\mathrm{T}$ cell recruitment to the sites of inflammation [219]. Among T cell subsets, IL-17-producing T cells are critical for the maintenance of AII-induced hypertension [220].

AT2R also participate as a major anti-inflammatory mediator in animal models of vascular injury [221] although its role of AT2R in the process of vascular inflammation is not fully understood. Thus, the sustained increase in BP in mice caused by $\mathrm{C}$-reactive 
protein (CRP), which is an inflammatory marker and independent predictor of incident hypertension, is associated with the reduction in vascular AT2R expression [222]. Also, in-vitro studies have shown that direct AT2R stimulation with compound 21 reduces the production of proinflammatory cytokines from cultured fibroblasts [223]. Furthermore, it has been shown that compound 21 preserves also renal structure and function by preventing inflammatory cell infiltration, collagen accumulation and the neoexpression of vimentin in spontaneously hypertensive rats [224].

In specific situations as $\mathrm{CKD}$, where the presence of an uremic state could play an important role, there are strong associations between proinflammatory cytokines and vascular complications, so several types of anticytokine treatment strategies have been proposed [210]. In this sense, there are some data showing the anti-inflammatory properties of ACEI and some of the beneficial effects of the RAS blockade may be related to such activities. Thus, in an experimental study Anderson et al. reported an impaired cytokine-induced nuclear factor- $\mathrm{kB}(\mathrm{NF}-\mathrm{kB})$ translocation from the cytoplasm to the nucleus in captopril preincubated monocytes [225]. In a clinical study Stevinkel at al. found low plasma levels of tumour necrosis factor- $\alpha$ (TNF- $\alpha$ ) and C-reactive protein (CRP) in ESRD patients treated with ACEI [226]. Trying to give a more clinical perspective of these studies it has been postulated from the data of SOLVD trial that those patients treated with an ACEI reduced the risk of weight loss, supporting the hypothesis of relationships among wasting, the RAS and inflammation [227].

In the case of type $2 \mathrm{DM}$ its pathogenesis is characterized by activation of complex molecular pathways, and emerging evidence now suggests that inflammatory pathways have a central role in the development of diabetic complications, such as diabetic nephropathy [228]. Type $2 \mathrm{DM}$ is associated with a myriad of deviations from normal homeostasis, including hemodynamic abnormalities, metabolic derangements, increased synthesis of hormones such as AII, and apparent increased vulnerability to the adverse effects of external noxious or proinflammatory factors. All these factors are associated with renal injury and induce the activation of diverse signal transduction systems in virtually all types of kidney cells. One of the major elements implicated in this inflammatory reaction is $\mathrm{NF}-\kappa \mathrm{B}$, a ubiquitous transcription factor that is activated by many stimuli relevant to diabetic nephropathy (including proinflammatory cytokines and mechanical forces). In turn, these signals trigger the synthesis and production of molecules involved in inflammatory pathways. NF- $\kappa \mathrm{B}$ is, therefore, a key nexus in the regulation of many chemokines, cell adhesion proteins, inflammatory cytokines and other molecules relevant to the pathogenesis of diabetic nephropathy. Proteinuria, a critical factor in the progression of diabetic nephropathy, is intimately related to inflammation [229]. Current experimental and clinical experience indicates that the severity of proteinuria is not only a reflection of the underlying glomerular injury, but that it directly contributes to tubular and interstitial damage through abnormal filtration of proteins, as well as by activation of cellular responses to the renal injury itself [230]. Proteinuria induces activation of renal tubular cells, which lead to expression of numerous chemokines, adhesion molecules and proinflammatory cytokines. In turn, these responses result in interstitial infiltration by monocytes, neutrophils and lymphocytes, which then contribute to renal cell injury, tubulointerstitial damage and fibrosis. Kidney cells can synthesize proinflammatory cytokines, and the expression of chemoattractant cytokines and adhesion molecules is upregulated in kidney cells from patients and animals with diabetes [228]. These molecules are key mediators of renal injury by virtue of their ability to attract circulating white blood cells (monocytes, neutrophils and lymphocytes) and facilitate transmigration of these cells into renal tissue. These infiltrating cells are also a source of cytokines and other mediators that contribute to the development and progression of renal injury, as well as to amplification and perpetuation of the inflammatory reaction. Today, growing evidence indicates that cytokines are important in the pathogenesis of microvascular complications in patients with diabetes mellitus, including diabetic nephropathy [211]. The activities of proinflammatory cytokines are, however, very complex, and this complexity must be taken into account when considering the role that these molecules have in the pathophysiology of diabetic nephropathy [211]. In the past few years, based in the mentioned evidence of an inflammatory mechanism in diabetic nephropathy, several treatments in current use are associated with actions on inflammatory pathways. For instance, the renoprotective effects conferred by ARBs are postulated to be at least partly related to anti-inflammatory actions that occur via the inhibition of NFkB-dependent pathways [231] In addition, Aldo receptor blockade in the kidneys of animals with experimental type $2 \mathrm{DM}$ has a renoprotective effect associated with an anti-inflammatory mechanism related to inhibition of $\mathrm{NF \kappa B}$ activation [232]. Finally in patients with diabetic nephropathy the combination of either ACEI [233] or ARB [234] with pentoxifylline, a xanthine derivative with modulating effects on TNF, has resulted in additive antiproteinuric effects. In one of these studies, a reduction in UAE was independently associated with a decrease in urinary TNF [234].

\section{Polymorphisms of RAAS}

Several polymorphisms of genes coding for components of the RAAS have been identified [235]. The exact mechanism by which the polymorphisms of RAAS could influence the progression of kidney disease is not clear. There are two main types of procedures tests used to detect which genes should be studied: association test, and transmission test for linkage disequilibrium, which is the more precise [236]. The ACE gene is a well-characterized locus that is associated with the pathogenesis and progression of CKD; polymorphisms of this gene affect response to treatment with ACEIs and ARBs [237]. Plasma and tissue levels of $\mathrm{ACE}$ are at least partially determined by a genetic polymorphism based on the presence (insertion [I]) or absence (deletion [D]) of a 287 base pair element in intron 16 [238]. In particular Asian subjects with the DD genotype (and increased ACE activity) have been reported to be at higher risk for cardiovascular disorders and nephropathy. Numerous studies evaluated the role of the ACE I/D polymorphism as well as other genetic variants of the RAAS in the context of RAAS inhibitor therapy. Among them polymorphism are I/D polymorphism, a variant of the angiotensinogen gen, the M235T polymorphism, and the variant A1166C polymorphism of the AII type-1 receptor gene [239]. Several studies have suggested a potential role for I/D polymorphism of the ACE gene in the progression of renal diseases and in the cardiovascular death complications rate of patients with CKD [240]. In relation to the variations of ACE serum levels, the presence of the genotype $\mathrm{D} / \mathrm{D}$ is associated with higher levels of the enzyme, while lower values are related to the presence of the genotype I/I [240]. Compared with insertion/deletion (I/D) and (D/D) genotypes, the I/I genotype protects against the development and progression of nephropathy in patients with type 1 and type $2 \mathrm{DM}$, possibly because it is associated with reduced plasma levels of ACE and decreased glucose-induced glomerular hyperfiltration [241]. The I/I genotype is associated with the greatest benefit from ACEI therapy among patients with diabetes who have normoalbuminuria or microalbuminuria, and the $\mathrm{D} / \mathrm{D}$ genotype is associated with the greatest benefit from ACEI therapy in 
those with macroalbuminuria. Independent of involved mechanisms, evaluating the ACE I/D polymorphism may help in identifying patients at risk of development or progression of nephropathy and those who might derive the greatest benefit from RAAS inhibition [237]. In the case of the polymorphisms of angiotensinogen, it has been described an association of higher level of circulating angiotensinogen with the allele T [239]. Finally, the variant A1166C polymorphism of the AII type-1 receptor gene is associated with an increase of the intrarrenal and peripheric activity of AII [242].

There are several studies trying to determine possible associations between RAAS polymorphisms and progression of kidney disease. In the REIN study, where a group of non-diabetic patients with chronic proteinuric nephropathies were studied, the ECA genotype did not disclosed any effect neither on the decrease of glomerular filtration rate nor in the incidence of ESRD [243]. Also, when angiotensinogen and AT1R polymorphisms were analyzed most of the studies did not disclose any definitive relation with renal disease progression [239]. However, in hypertensive patients it has been suggested that the combination of unfavorable polymorphisms (DD type for ECA, TT for angiotensinogen and AC/CC for AII-type-1 receptor gene) could contribute in a synergistic way to the presence of target organ damages [244]. The relation between the degree of response to renoprotective therapies and polymorphisms types has been matter of concern, although the results are inconclusive. A subanalysis of REIN study showed that only men with the DD type had a favourable response to the treatment with ramipril [245].

In summary, to date results on RAAS polymorphisms as determinants of the prevalence of renal diseases and the response to renoprotective therapies are conflicting. Given the polygenic nature of renal and CVD and the growing number of candidates genes, large prospective and collaborative studies are required to assess the efficacy of RAAS blockade therapies in relation with these possible associations. In these sense pharmacogenetics and pharmacogenomics involve the search for genetic polymorphisms that influence response to drug therapy [246]. These disciplines offer the opportunity to provide individualized drug therapy on the basis of the genetic profile persons, thus increasing the likelihood of achieving treatment goals and limiting adverse effects from drug therapy.

\section{Pharmacogenomics in RAAS Blockade}

The concept of "pharmacogenomics" and "pharmacogenetics" that appears in the post-genome era, offers the ultimate personalized medicine, by which favorable effects of medications are maximized and adverse effects are minimized, compared with conventional "trial and error" prescribing. The RAAS is one of the most plausible candidates for the application of this approach in the area of cardiovascular medicine. However previous reports on this issue did not showed consistent conclusions [246,247] due to a severa limitations such as race, patient selection, salt intake, combining of different therapies, drug dose, administration term and drug selection, statistical power, combining of different alleles, and end points such as definition of responders [247]. Recently, Konoshita published a complete review of the current studies with a minimum sample size of 200 subjects in order to increase their statistical power [248]. This review showed relatively consistent results, concluding that the conventional genetic variants of the system-the ACE I/D, AGT M235T, AT1 A1166C, and AT2 variantare not associated with the antihypertensive effects of RAAS blockade, at least by individual SNPs. In contrast, significant associations have been reported with AGT rs7079, AT1 haplotype, REN, and ACE2, each in one report. For these variants, further evaluations are expected. However, much more must be learned before pharmacogenetic factors can be routinely incorporated into therapeutic decisions.

\section{The Economic Perspective on RAAS Blockade in Kidney Disease, Hypertension and Diabetes}

The cost is a key factor to be considered in any therapeutic decision that hold the remarkable implications as RAAS blockade has. A number of strategies have been devised to increase the access to essential medicine where they are most needed [249]. The decision of which agents to use will have to be tailored carefully to the needs of the patient and careful consideration of both medical and economic factors. However, whichever type of agent is used, treatment costs are likely to be substantial. Based on these facts, in some countries there is an increasing necessity to include in every new drug an economic evaluation inform together with the drug pharmacological information, in order to permit its inclusion in health reimbursement policies [250]

The economic impact of even partial improvement of renal function would be enormuos, as documented by findings that a $30 \%$ reduction in the rate of GFR decline would translate into savings of more than 60 billion dollars for providing renal replacement therapy to patients progressing to ESRD in the US by year 2010 [251]. The incidence of ESRD is increasing worldwide. These increases represent a significant burden to countries worldwide; not only due to the financial costs of providing ESRD care, but also because of lost productivity and significant morbidity and mortality for the affected patients. There is clearly a pressing need for the aggressive identification and early treatment of patients with nephropathy to prevent progression to ESRD [252]. As it has already been said, there are now evidence of effective treatment options that can slow the progression of chronic nephropathies in many individuals, and ongoing research has raised the tantalizing prospect of the reversal of renal disease progression [253].

A joint national committee at the National Heart Lung and Blood Institute of the US National Institutes of Health recommended in 2004 that thiazide diuretics should be used as initial treatment for most patients with hypertension [254]. However, the cost of ACEIs has declined steeply since 2004. The 2006 NICE guideline on hypertension includes a health economic model, its sensitivity analysis showed that drugs that inhibit the RAAS were likely to be the most cost effective option in such patients [255]. For ARBs, these drugs are much more expensive that $\mathrm{ACE}$ inhibitors and so are best reserved for patients who cannot tolerate ACE inhibitors because of cough or angio-oedema. The cost of ARBs is expected to fall noticeably as non-proprietary formulations are developed. Differences between individual ARBs are mainly pharmacokinetic, and in view of the excellent evidence base for losartan, cost benefit strongly favours use of this drug when an ARB is indicated for hypertension.

The increasing prevalence of type 2 diabetes has drawn much concern in economic issues as the primary consideration in discussions for treatment of diabetic nephropathy. But in the end, the economics of treatment are driven by clinical issues, many of which have yet to be resolved. Regardless of the exact dollar figures, the increase in the rate of diabetic nephropathy will undoubtedly strain the economies of all countries. In addition to the macroeconomic impact, we must contend with the costs of drugs that are used to limit kidney damage caused by diabetes [256]. Among several possible funding strategies, a global fund for kidney diseases has been proposed. Drug companies, whose products such as ACEI and other antihypertensive drugs, have proved 
Citation: Macia-Heras M, Del Castillo-Rodriguez N, Navarro González JF (2012) The Renin-Angiotensin-Aldosterone System in Renal and Cardiovascular Disease and the Effects of its Pharmacological Blockade. J Diabetes Metab 3:171. doi:10.4172/2155-6156.1000171

Page 18 of 24

to be very profitable, and could support such a fund with a minimal percentage of the revenues from antihypertensive [257].

\section{Conclusions}

The RAAS is a coordinated hormonal cascade that regulates fluid and electrolyte balance and arterial pressure, and it plays a major role in cardiovascular, renal, and adrenal function. In the classic view of the RAAS, AII, the biologically active octapeptide, is generated by a 2-step enzymatic process in which its precursor, the inactive decapeptide $\mathrm{AI}$, is cleaved from angiotensinogen by renin, a glycosylated aspartyl protease secreted by the renal juxtaglomerular granular epithelioid cells. The second step of AII synthesis is the removal of the C-terminal dipeptide of AI by ACE. This enzyme has multiple substrates, in vivo it cleaves and thus inactivates $\mathrm{BK}$, a vasodilator and natriuretic peptide, substance $\mathrm{P}$ and also AcSDKP, a hemoregulatory peptide. AII binds to its receptors to activate intracellular signals, and it also very rapidly is cleaved by other enzymes, such as angiotensinases, into other shorter angiotensin-related peptides (AIII, A[1-7], and A[3-8]). Although $\mathrm{A}(1-7)$ and $\mathrm{A}(3-8)$ are biologically active, their functions in vivo have not been elucidated fully. The majority of the effects of AII-vascular smooth muscle cell contraction and pressor response, aldosterone secretion, inhibition of renin release, renal sodium reabsorption, vasopressin secretion, dipsogenic responses, generation of growthpromoting cytokines, free oxygen radicals, and fibrosis mediators in tissues-are mediated by the AT1R. AII also binds the AT2R whose functions remain controversial. This view of the RAAS has been expanded by additional findings. First, numerous studies have proven the importance of a local tissue RAAS in the kidney, brain, heart, blood vessels, and adrenal glands in mediating diverse physiologic functions. Second, alternative non-ACE-dependent pathways of AII generation, such as chymase and chymotrypsin-like angiotensin-generating enzyme, and new enzymes such as ACE2, have been described. In vitro ACE2 hydrolyzes AI to A(1-9), AII to A(1-7), and BK to des-Arg9-BK and other substrates, but its functions in vivo remain to be elucidated. ACE2 counterbalances the functions of ACE and the balance between these 2 proteases may determine local and systemic levels of RAAS peptides such as AII and A(1-7). Third, other receptors (AT4R) and other signaling pathways have been characterized. The discovery of the prorenin/renin receptor has given renin and prorenin a direct biological role in stimulating intracellular pathways independently of AII. We must emphasize the important significance that has had the better knowledge and understanding of the RAAS in the treatment of CVD and renal diseases and their clinical implications. The synthesis of the first orally active ACEI, captopril fostered the development of new therapeutic paradigms and opened a new era of research. The efficacy of RAAS blockers in treating hypertension, HF and renal diseases has been gradually demonstrated in several clinical trials. Treatment of hypertension also benefited from the subsequent discovery of AII antagonists, selectively blocking AT1R activation without influencing the vasodilatory kinins. The beneficial effect of inhibition of RAAS activity by ACEI or ARB in patients with left ventricular dysfunction or systolic HF is well established. Treatment with ACEI or ARB decreases mortality rate and reduces the risk for adverse cardiovascular outcome in high-risk patients with coronary artery disease, independently of the BP control. Intensive treatment with ACEI of diabetic patients with microalbuminuria results in renoprotection and cardioprotection. In patients with non-diabetic chronic nephropathies, the integrated intervention including the use of ACEI, together with ARB stabilizes the glomerular filtration rate and induces remission of the disease. This approach has suggested that RAAS blockers, by preventing progressive kidney function loss, possibly contribute to kidney repair. At present the results of large clinical trials has opened the question about the most adequate indications for agents blocking the RAAS depending on their site of action and to what patient population will obtain the highest benefits in terms of cardiovascular protection with a proper balance between clinical results and the appearance of associated adverse events. Finally, while studying the beneficial effects of RAAS blockade on heart and kidney, emerging evidence showed additional activities of RAAS antagonists as anti-inflammatory and immunomodulatory agents and paved the way to new potential applications of these drugs in autoimmune diseases. The challenge for the next years is to establish whether these may translate in new medical applications of these drugs.

\section{Acknowledgements}

Funding for author Manuel Macía Heras was via Spanish Society of Nephrology. We thank Dr. Jorge Salazar from Novartis for assistance with figures.

\section{References}

1. Lloyd-Jones D, Adams R, Carnethon M, De Simone, Ferguson TB, et al. (2009) Heart disease and stroke statistics-2009 update: A report from the American Heart Association Statistics Committee and Stroke Statistics Subcommittee. Circulation 119: 480-486.

2. Chobanian AV, Bakris GL, Black HR, Cushman WC, Green LA, et al. (2003) Seventh report of the Joint National Committee on Prevention, Detection, Evaluation, and Treatment of High Blood Pressure. Hypertension 42: 12061252

3. Eknoyan G, Hostetter T, Bakris GL, Hebert L, Levy AS, et al. (2003) Proteinuria and other markers of chronic kidney disease: A position statement of the national kidney foundation (NKF) and the national institute of diabetes and digestive and kidney diseases (NIDDK). Am J Kidney Dis 42: 617-622.

4. Hillege HL, Janssen WM, Bak AA, Diercks GF, Grobbee DE, et al. (2001) Microalbuminuria is common, also in a nondiabetic, nonhypertensive population, and an independent indicator of cardiovascular risk factors and cardiovascular morbidity. J Intern Med 249: 519-526.

5. Ninomiya T, Perkovic V, de Galan BE, Zoungas S, Pillai A, et al. (2009) Albuminuria and kidney function independently predict cardiovascular and renal outcomes in diabetes. J Am Soc Nephrol 20: 1813-1821.

6. Dzau VJ (2001) Theodore Cooper Lecture: Tissue angiotensin and pathobiology of vascular disease: a unifying hypothesis. Hypertension 37: 1047-1052.

7. Remuzzi G, Benigni A, Remuzzi A (2006) Mechanisms of progression and regression of renal lesions of chronic nephropathies and diabetes. J Clin Invest 116: $288-296$.

8. Yvan-Charvet L, Quignard-Boulange A (2011) Role of adipose tissue reninangiotensin system in metabolic and inflammatory diseases associated with obesity. Kidney Int 79: 162-168.

9. Perico N, Benigni A, Remuzzi G (2008) Present and future drug treatments for chronic kidney diseases: evolving targets in renoprotection. Nat Rev Drug Discov 7: 936-953.

10. Slagman MCJ, Navis G, Laverman GD (2010) Dual blockade of the reninangiotensin-aldosterone system in cardiac and renal disease. Curr Opin Nephrol Hypertens 19: 140-152.

11. Ferrario CM (2006) Role of angiotensin II in cardiovascular disease therapeutic implications of more than a century of research. J Renin Angiotensin Aldosterone Syst 7: 3-14.

12. Brewster UC, Perazella M A (2004) The renin-angiotensin-aldosterone system and the kidney: effects on kidney disease. Am J Med 116: 263-272.

13. Zaman MA, Oparil S, Calhoun DA (2002) Drugs targeting the renin-angiotensinaldosterone system. Nat Rev 1: 621-636.

14. Carey RM, Siragy HM (2003) Newly recognized components of the reninangiotensin system: potential roles in cardiovascular and renal regulation Endocr Rev 24: 261-271.

15. Boehm M, Nabel EG (2004) Angiotensin-Converting Enzyme 2 - A New Cardiac Regulator. N Eng J Med 347: 1795-1797. 
Citation: Macia-Heras M, Del Castillo-Rodriguez N, Navarro González JF (2012) The Renin-Angiotensin-Aldosterone System in Renal and Cardiovascular Disease and the Effects of its Pharmacological Blockade. J Diabetes Metab 3:171. doi:10.4172/2155-6156.1000171

16. Ferrario CM (2003) Contribution of angiotensin-(1-7) to cardiovascular physiology and pathology. Curr Hypertens Rep 5: 129-134.

17. Santos RA, Simoes e Silva AC, Maric C, Silva DM, Machado RP, et al. (2003) Angiotensin-(1-7) is an endogenous ligand for the $G$ protein-coupled receptor Mas. Proc Natl Acad Sci USA 100: 8258-8263.

18. Chappell MC (2007) Emerging evidence for a functional angiotensin-converting enzyme 2-angiotensin-(1-7)-MAS receptor axis: more than regulation of blood pressure. Hypertension 50: 596-599.

19. Kim S, Iwao H (2000) Molecular and cellular mechanisms of angiotensin IImediated cardiovascular and renal diseases. Pharmacol Rev 52: 11-34.

20. Nguyen G (2011) Renin and Prorenin Receptor in Hypertension: What's New? Curr Hypertens Rep 13: 79-85.

21. Sihn G, Rousselle A, Vilianovitch L, Burckle C, Bader M (2010) Physiology of the (pro)renin receptor: Wnt of change? Kidney Int 78: 246-256.

22. Nguyen G, Delarue F, Burckle C, Bouzhir L, Giller T, et al. (2002) Pivotal role of the renin/prorenin receptor in angiotensin II production and cellular responses to renin. J Clin Invest 109: 1417-1427.

23. Staessen JA, Li Y, Richart T (2006) Oral renin inhibitors. The Lancet 368: 14491456.

24. Danser AH, Deinum J (2005) Renin, prorenin and the putative (pro)renin receptor. Hypertension 46: 1069-1076.

25. Krop M, Danser AH (2008) Circulating versus tissue renin-angiotensin system: on the origin of (pro)renin. Curr Hypertens Rep 10: 112-118.

26. Stankovic AR, Fisher ND, Hollenberg NK (2006) Prorenin and angiotensindependent renal vasoconstriction in type 1 and type 2 diabetes. J Am Soc Nephrol 17: 3293-3299.

27. Aros C, Remuzzi G (2002) The renin-angiotensin system in progression, remission and regression of chronic nephropathies. J Hypertens Suppl 20: 4553.

28. Morgan T (2003) Renin, angiotensin, sodium and organ damage. Hypertens Res 26: 349-354.

29. Harris RC, Martinez-Maldonado M (1995) Angiotensin II-mediated renal injury. Miner Electrolyte Metab 21: 328-335.

30. Ruiz-Ortega M, Lorenzo O, Suzuki Y, Ruperez M, Egido J (2001) Proinflammatory actions of angiotensins. Curr Opin Nephrol Hypertens 10: 321 329.

31. Eddy AA (2001) Plasminogen activator inhibitor-1 and the kidney. Am J Physio Renal Physiol 283: F209-F220.

32. Hostetter T (2004) Aldosterone in the development and progression of renal injury. Kidney Int 66: 1-9.

33. Agarwala R, Campbell RC (2004) Oxidative stress in hypertension and chronic kidney disease: role of angiotensin II. Sem Nephrol 24: 101-114.

34. Wilcox CS (2002) Reactive oxygen species: Roles in blood pressure and kidney function. Curr Hypertens Rep 4: 160-166

35. Stegbauer J, Coffman TM (2011) New insights into angiotensin recepto actions: from blood pressure to aging. Curr Opin Nephrol Hypertens 20: 84-88.

36. Timmermans P, Chiu A, Herblin W, Wong PC (1992) Angiotensin II receptor subtypes. Am J Hypertens 5: 406-410.

37. Guilluy C, Bregeon J, Toumaniantz G, Rolli-Derkinderen M, Retailleau K, et al (2010) The Rho exchange factor Arhgef1 mediates the effects of angiotensin II on vascular tone and blood pressure. Nat Med 16:183-190.

38. Savoia C, D'Agostino M, Lauri F, Volpe M (2011) Angiotensin type 2 receptor in hypertensive cardiovascular disease. Curr Opin Nephrol Hypertens 20: 125132

39. Kaschina E, Grzesiak A, Li J, Foryst-Ludwig A, Timm M, et al. (2008) Angiotensin II type 2 receptor stimulation: a novel option of therapeutic interference with the renin-angiotensin system in myocardial infarction? Circulation 118: 2523-2532.

40. Carey RM, Xue C, Abadir P, Siragy HM (2005) Angiotensin subtype-2 receptors inhibit renin biosynthesis and angiotensin II formation. Hypertension 45: 133137
41. Levy BI (2005) How to explain the differences between renin-angiotensin system modulators. Am J Hypertens 18: S134-S141.

42. Savoia C, Touyz RM, Volpe M, Schiffrin EL (2007) Angiotensin type 2 receptor in resistance arteries of type 2 diabetic hypertensive patients. Hypertension 49: $341-346$

43. Savoia C, Touyz RM, Endemann D, Pu Q, Ko EA, et al. (2006) Angiotensin receptor blocker added to previous antihypertensive agents on arteries of diabetic hypertensive patients. Hypertension 48: 271-277.

44. Wan Y, Wallinder C, Plouffe B, Beaudry H, Mahalingham AK, et al. (2004) Design, synthesis, and biological evaluation of the first selective nonpeptide AT2 receptor agonist. J Med Chem 47: 5995-6008

45. Schrier RW, Masoumi A, Elhassan E (2010) Aldosterone: Role in Edematous Disorders, Hypertension, Chronic Renal Failure, and Metabolic Syndrome. Clin J Am Soc Nephrol 5: 1132-1140.

46. Fiebeler A, Muller DN, Shagdarsuren E, Luft FC (2007) Aldosterone, mineralocorticoid receptors, and vascular inflammation. Curr Opin Nephro Hypertens 16: 134-142.

47. Sowers JR, Whaley-Connell A, Epstein M (2009) Narrative review: The emerging clinical implications of the role of aldosterone in the metabolic syndrome and resistant hypertension. Ann Intern Med 150: 776-783.

48. Leroy V, De Seigneux S, Agassiz V, Hasler U, Rafestin-Oblin ME, et al. (2009) Aldosterone activates NF-kappaB in the collecting duct. J Am Soc Nephrol 20 131-144.

49. Hensen J, Abraham WT, Durr JA, Schrier RW (1991) Aldosterone in congestive heart failure: Analysis of determinants and role in sodium retention. Am J Nephrol 11: 441-446.

50. Pitt B, Zannad F, Remme WJ, Cody R, Castaigne A, et al. (1999) The effect of spironolactone on morbidity and mortality in patients with severe heart failure. Randomized Aldactone Evaluation Study Investigators. N Engl J Med 341: 709 717

51. Pitt B, Bakris G, Ruilope LM, DiCarlo L, Mukherjee R (2008) EPHESUS Investigators: Serum potassium and clinical outcomes in the Eplerenone Post-Acute Myocardial Infarction Heart Failure Efficacy and Survival Study (EPHESUS). Circulation 118: 1643-1650.

52. Juurlink D, Mamdani M, Lee DS, Kopp A, Austin PC, et al. (2004) Rates of hyperkalemia after publication of the Randomized Aldactone Evaluation Study. N Engl J Med 351: 543-551.

53. Gheorghiade M, Filippatos G (2005) Reassessing treatment of acute heart failure syndromes: The ADHERE registry. Eur Heart J 7: B13-B19

54. Jain G, Campbell RC, Warnock DG (2009) Mineralocorticoid receptor blockers and chronic kidney disease. Clin J Am Soc Nephrol 4: 1685-1691.

55. Chapman N, Dobson J, Wilson S, Dahlöf B, Sever PS, et al. (2007) AngloScandinavian Cardiac Outcomes Trial Investigators: Effect of spironolactone on blood pressure in subjects with resistant hypertension. Hypertension 49 839-845.

56. Brown NJ (2008) Aldosterone and vascular inflammation. Hypertension 51: 161-167.

57. Toto RD (2010) Aldosterone blockade in chronic kidney disease: can it improve outcome? Curr Opin Nephrol Hypertens 19: 444-449.

58. Bianchi S, Bigazzi R, Campese VM (2006) Long-term effects of spironolactone on proteinuria and kidney function in patients with chronic kidney disease. Kidney Int 70: 2116-2123.

59. Chrysostomou A, Pedagogos E, MacGregor L, Becker G (2006) Double-blind, placebo-controlled study on the effect of the aldosterone receptor antagonis spironolactone in patients who have persistent proteinuria and are on long-term angiotensin-converting enzyme inhibitor therapy, with or without an angiotensin II receptor blocker. Clin J Am Soc Nephrol 1: 256-262.

60. van den Meiracker AH, Baggen RG, Pauli S, Lindemans A, Vulto AG, et al. (2006) Spironolactone in type 2 diabetic nephropathy: Effects on proteinuria blood pressure and renal function. J Hypertens 24: 2285-2292.

61. Tikellis C, Bernardi S, Burns WC (2011) Angiotensin-converting enzyme 2 is a key modulator of the renin-angiotensin system in cardiovascular and renal disease. Curr Opin Nephrol Hypertens 20: 62-68. 
Citation: Macia-Heras M, Del Castillo-Rodriguez N, Navarro González JF (2012) The Renin-Angiotensin-Aldosterone System in Renal and Cardiovascular Disease and the Effects of its Pharmacological Blockade. J Diabetes Metab 3:171. doi:10.4172/2155-6156.1000171

62. Donoghue M, Hsieh F, Baronas E, Godbout K, Gosselin M, et al. (2000) A novel angiotensin converting enzyme-related carboxypeptidase (ACE2) converts angiotensin I to angiotensin 1-9. Circ Res 87: E1-E9.

63. Ferrario CM (2011) ACE2: more of Ang-(1-7) or less Ang II? Curr Opin Nephrol Hypertens 20: 1-6.

64. Ferrario CM, Varagic $\mathrm{J}$ (2010) The ANG-(1-7)/ACE2/Mas axis in the regulation of nephron function. Am J Physiol Renal Physiol 298: F1297-F1305.

65. Crackower MA, Sarao R, Oudit GY, YagilC, Kozieradzki I, et al. (2002) Angiotensin-converting enzyme 2 is an essential regulator of heart function. Nature 417: 822-828.

66. Zisman LS, Keller RS, Weaver B, Lin Q, Speth R, et al. (2003) Increased angiotensin-(1-7)-forming activity in failing human heart ventricles: evidence for upregulation of the angiotensin-converting enzyme homologue ACE2. Circulation 108: 1707-1712.

67. Wysocki J, Ye M, Rodriguez E, Gonzalez-Pacheco FR, Barrios C, et al. (2010) Targeting the degradation of angiotensin II with recombinant angiotensinconverting enzyme 2: prevention of angiotensin II-dependent hypertension. Hypertension 55: 90-98.

68. Ferrario CM, Chappell MC, Tallant EA, Brosnihan KB, Diz DI (1997) Counterregulatory actions of angiotensin-(1-7). Hypertension 30: 535-541.

69. Luque M, Martin P, Martell N, Fernandez C, Brosnihan, et al. (1996) Effects of captopril related to increased levels of prostacyclin and angiotensin-(1-7) in essential hypertension. J Hypertens 14: 799-805.

70. Ferrario CM, Martell N, Yunis C, et al. (1998) Characterization of angiotensin-(1-7) in the urine of normal and essential hypertensive subjects. Am J Hypertens 11: 137-146.

71. Navar LG (2004) The intrarenal renin-angiotensin system in hypertension Kidney Int 65: 1522-1532.

72. Dilauro M, Burns KD (2009) Angiotensin-(1-7) and its effects in the kidney. Sc World J 9: 522-535.

73. Reich HN, Oudit GY, Penninger JM, Scholey JW, Herzenberg A (2008) Decreased glomerular and tubular expression of ACE2 in patients with type 2 diabetes and kidney disease. Kidney Int 74: 1610-1616.

74. Cesari M, Rossi GP, Pessina AC (2002) Biological properties of the angiotensin peptides other than angiotensin II: implications for hypertension and cardiovascular disease. J Hypertens 20: 793-799.

75. Banegas I, Prieto I, Vives F, Alba F, de Gasparo M, et al. (2006) Brain aminopeptidases and hypertension. J Renin Angiotensin Aldosterone Syst 7 $129-134$

76. Allred AJ, Diz DI, Ferrario CM, Chappell MC (2000) Pathways for angiotensin-(1-7) metabolism in pulmonary and renal tissues. Am J Physiol Renal Physiol 279: F841-F850.

77. Nagata S, Kato J, Sasaki K, Minamino N, Eto T, et al. (2006) Isolation and identification of proangiotensin-12, a possible component of the reninangiotensin system. Biochem Biophys Res Commun 350: 1026-1031.

78. Azizi M, Webb R, Nussberger J, Hollenberg NK (2006) Renin inhibition with aliskiren: where are we now, and where are we going? J Hypertens 24: 243-

79. Azizi M, Wuerzner G (2007) Rationale for Combining Blockers of the ReninAngiotensin System. Semin Nephrol 27: 544-554.

80. Strauss MH, Hall AS (2006) Angiotensin receptor blockers may increase risk of myocardial infarction: unraveling the ARB-MI paradox. Circulation 114: 838854

81. Tsuyuki RT, McDonald MA (2006) Angiotensin receptor blockers do not increase risk of myocardial infarction. Circulation 114: 855-860.

82. Azizi M, Menard J (2004) Combined blockade of the renin-angiotensin system with angiotensin-converting enzyme inhibitors and angiotensin II type 1 receptor antagonists. Circulation 109: 2492-2499.

83. Turnbull $F$ (2003) Effects of different blood-pressure-lowering regimens on major cardiovascular events: results of prospectively-designed overviews of randomized trials. Lancet 362: 1527-1535.

84. Maione A, Navaneethan SD, Graziano G, Mitchell R, Johnson D, et al. (2011) Angiotensin-converting enzyme inhibitors, angiotensin receptor blockers and combined therapy in patients with micro- and macroalbuminuria and othe cardiovascular risk factors: a systematic review of randomized controlled trials. Nephrol Dial Transplant 26: 2827-2847.

85. Matchar DB, McCrory DC, Orlando LA, Patel UD, Patwardhan MB, et al. (2008) Systematic review: Comparative effectiveness of angiotensin-converting enzyme inhibitors and angiotensin II receptor blockers for treating essential hypertension. Ann Intern Med 148: 16-29.

86. McDonald MA, Simpson SH, Ezekowitz JA, Gyenes G, Tsuyuki RT (2005) Angiotensin receptor blockers and risk of myocardial infarction: Systematic review. BMJ 331: 873-878

87. Sarafidis PA, Stafylas PC, Kanaki Al, Lasaridis AN (2008) Effects of reninangiotensin system blockers on renal outcomes and all-cause mortality in patients with diabetic nephropathy: an updated meta-analysis. Am J Hypertens 21: 922-929.

88. Reboldi G, Angeli F, Cavallini C, Gentile G, Mancia G, et al. (2008) Comparison between angiotensin-converting enzyme inhibitors and angiotensin recepto blockers on the risk of myocardial infarction, stroke and death: a meta-analysis. J Hypertens 26: 1282-1289.

89. Kunz R, Friedrich C, Wolbers M, Mann JF (2008) Meta-analysis: effect of monotherapy and combination therapy with inhibitors of the renin angiotensin system on proteinuria in renal disease. Ann Intern Med 148: 30-48.

90. Schrier RW (2010) Hyperkalemia: a threat to RAAS inhibition? Nat Rev Nephrol 6: $245-246$.

91. Smith CG, Vane JR (2003) The discovery of captopril. FASEB 17: 788-789.

92. Flather MD, Yusuf S, Kober L, Pfeffer M, Hall A, et al. (2000) Long-term ACEinhibitor therapy in patients with heart failure or left-ventricular dysfunction: systematic overview of data from individual patients. ACE-Inhibitor Myocardial Infarction Collaborative Group. Lancet 355: 1575-1581.

93. ACE Inhibitor Myocardial Infarction Collaborative Group (1998) Indications for ACE inhibitors in the early treatment of acute myocardial infarction. Circulation 97: 2202-2212

94. Yusuf S, Sleight P, Pogue J, Bosch J, Davies R, et al. (2000) Effects of an angiotensin-converting-enzyme inhibitor, ramipril, on cardiovascular events in high-risk patients. The Heart Outcomes Prevention Evaluation Study Investigators. N Engl J Med 342: 145-153.

95. Fox KM, The European Trial on Reduction of Cardiac Events With Perindopril in Stable Coronary Artery Disease Investigators (2003) Efficacy of perindopril in reduction of cardiovascular events among patients with stable coronary artery disease: randomized, double-blind, placebo-controlled, multi-centre trial (the EUROPA study) Lancet 362: 782-788.

96. Ruggenenti P, Perna A, Remuzzi G, Investigators of the GISEN Group (2003) Retarding progression of chronic renal disease: The neglected issue of residual proteinuria. Kidney Int 63: 2254-2261.

97. Gradman AH, Basile JN, Carter BL, Bakris GL (2010) Combination Therapy in hypertension. J Am Soc Hypertens 4: 42-50

98. Hsueh WA, Wyne K (2011) Renin-Angiotensin-Aldosterone System in Diabetes and Hypertension. J Clin Hypertens 13: 224-237.

99. Sica DA (2001) Pharmacology and clinical efficacy of angiotensin-receptor blockers. Am J Hypertens 14: S242-S247.

100.Conlin PR, Spence JD, Williams B, Ribeiro AB, Saito I, et al. (2000) Angiotensin II antagonists for hypertension: Are there differences in efficacy? Am J Hypertens 13: 418-426.

101. Sica DA (2009) Class-Effect with Antihypertensive Medications: Pharmacologic Considerations. J Clin Hypertens 11: S13-S18.

102. Sica DA (2005) Pharmacotherapy review: Angiotensin-receptor blockers. $J$ Clin Hypertens 7: 681-684.

103. Cohn JN, Tognoni G (2001) Valsartan heart failure trial investigators. A randomized trial of the angiotensin-receptor blocker valsartan in chronic heart failure. N Engl J Med 345: 1667-1675.

104. Pitt S, Poole-Wilson PA, Segal R, Martinez FA, Dickstein K, et al. (2000) Effect of losartan compared with captopril on mortality in patients with symptomatic heart failure: randomised trial-the Losartan Heart Failure Survival Study ELITE II. Lancet 355: 1582-1587.

105. Benson SC, Pershadsingh HA, Ho Cl, Chittiboyina A, Desai P, et al. (2004) 
Citation: Macia-Heras M, Del Castillo-Rodriguez N, Navarro González JF (2012) The Renin-Angiotensin-Aldosterone System in Renal and Cardiovascular Disease and the Effects of its Pharmacological Blockade. J Diabetes Metab 3:171. doi:10.4172/2155-6156.1000171

Identification of telmisartan as unique angiotensin II receptor antagonist with selective PPAR-modulating activity. Hypertension 43: 993-1002.

106. Wright JT, Bakris GL, Bell DSH, Fonseca V, Katholi RE, et al. (2007) Lowering Blood Pressure With $\beta$-Blockers in Combination With Other Renin-Angiotensin System Blockers in Patients With Hypertension and Type 2 Diabetes: Results From the GEMINI Trial. J Clin Hypertens 9: 842-849.

107. Remuzzi G, Bertani T (1998) Pathophysiology of progressive nephropathies N Eng J Med 339: 1448-1456.

108. Zatz R, Dunn BR, Meyer TW, Anderson S, Rennke HG, et al. (1986) Prevention of diabetic glomerulopathy by pharmacological amelioration of glomerular capillary hypertension. J Clin Invest 77: 1925-1930.

109. Remuzzi A, Perico N, Amuchastegui CS, Malanchini B, Mazerska M, et al. (1993) Short- and long-term effect of angiotensin II receptor blockade in rats with experimental diabetes. J Am Soc Nephrol 4: 40-49.

110. Schieppati A, Remuzzi G (2003) The future of renoprotection: Frustrations and promises. Kidney Int 64: 1947-1955.

111. Zoja C, Corna D, Camozzi D, Cattaneo D, Rottoli D, et al. (2002) How to fully protect the kidney in a severe model of progressive nephropathy: a multidrug approach. J Am Soc Nephrol 13: 2898-2908.

112. Fogo $A B(2003)$ The potential for regression of renal scarring. Curr Op Nephro Hyperten 12: 223-225

113. Remuzzi A, Gagliardini E, Donadoni C, Fassi A, Sangalli F, et al. (2002) Effect of angiotensin II antagonism on the regression of kidney disease in the rat. Kidney Int 62: 885-894.

114. Remuzzi G, Remuzzi A (2005) Is Regression of Chronic Nephropathies a Therapeutic Target? J Am Soc Nephrol 16: 840-842.

115. Remuzzi A, Mazerska M, Gephardt GN, Novick AC, Brenner BM, et al. (1995) Three-dimensional analysis of glomerular morphology in patients with subtotal nephrectomy. Kidney Int 48: 155-162.

116. Ruggenenti P, Cravedi P, Remuzzi G (2009) Proteinuria: Increased angiotensin-receptor blocking is not the first option. Nat Rev Nephrol 5: 367368 .

117. Ruggenenti P, Schieppati A, Remuzzi G (2001) Progression, remission, regression of chronic renal diseases. Lancet 357: 1601-1608.

118. Nobakht N, Kamgar M, Rastogi, Schrier RW (2011) Limitations of angiotensin inhibition. Nat Rev Nephrol 7: 356-359.

119. Mauer M, Zinman B, Gardiner R, Suissa S, Sinaiko A, et al. (2009) Renal and retinal effects of enalapril and losartan in type 1 diabetes. N Engl J Med 361: $40-51$.

120. Barlovic DP, Cooper ME (2009) RAS inhibition: probably not a one-size-fits-al approach. Nat Rev Nephrol 5: 669-670.

121. Remuzzi G, Ruggenenti P (2006) Overview of randomised trials of ACE inhibitors. Lancet 368: 555-556.

122. Bertrand ME (2004) Provision of cardiovascular protection by ACE inhibitors: a review of recent trials. Curr Med Res Opin 20: 1559-1569.

123. Al-Mallah MH, Tleyjeh IM, Abdel-Latif AA, Weaver WD (2006) Angiotensin converting enzyme inhibitors in coronary artery disease and preserved left ventricular systolic function: a systematic review and meta-analysis of randomized controlled trials. J Am Coll Cardiol 47: 1576-1583.

124.Dagenais GR, Pogue J, Fox K, Simoons ML, Yusuf S (2006) Angiotensinconverting-enzyme inhibitors in stable vascular disease without left ventricular systolic dysfunction or heart failure: a combined analysis of three trials. Lancet 368: $581-588$

125. Khan NA, Ma I, Thompson CR, Humphries K, Salem DN, et al. (2006) Kidney function and mortality among patients with left ventricular systolic dysfunction. J Am Soc Nephrol 17: 244-253.

126. Bakris GL, Weir MR (2000) Angiotensin-converting enzyme inhibitorassociated elevations in serum creatinine: is this a cause for concern? Arch Intern Med 160: 685-693.

127. Schoolwerth AC, Sica DA, Ballermann BJ, Wilcox CS (2001) Renal considerations in angiotensin converting enzyme inhibitor therapy: a statement for healthcare professionals from the Council on the Kidney in Cardiovascular
Disease and the Council for High Blood Pressure Research of the American Heart Association. Circulation 104: 1985-1991.

128. Shlipak MG (2003) Pharmacotherapy for heart failure in patients with rena insufficiency. Ann Intern Med 138: 917-924.

129. Palmer BF (2004) Managing hyperkalemia caused by inhibitors of the reninangiotensin-aldosterone system. N Engl J Med 351: 585-592.

130. Pitt B, Segal R, Martinez FA, Meurers G, Cowley AJ, et al. (1997) Randomised trial of losartan versus captopril in patients over 65 with heart failure (Evaluation of Losartan in the Elderly Study, ELITE). Lancet 349: 747-752.

131. McMurray J, Cohen-Solal A, Dietz R, Eichhorn E, Erhardt L, et al. (2005) Practical recommendations for the use of ACE inhibitors, beta-blockers aldosterone antagonists and angiotensin receptor blockers in heart failure: putting guidelines into practice. Eur J Heart Fail 7: 710-721.

132. Berger AK, Duval S, Manske C, Vazquez G, Barber C, et al. (2007) Angiotensin-converting enzyme inhibitors and angiotensin receptor blockers in patients with congestive heart failure and chronic kidney disease. Am Heart 153: 1064-1073.

133. Benjamin EJ, Wolf PA, D'agostino RB, Silbershatz H, Kannel WB, et al. (1998) Impact of atrial fibrillation on the risk of death: the Framingham Heart Study. Circulation 98: 946-952.

134. Boldt A, Wetzel U, Weigl J, Garbade J, Lauschke J, et al. (2003) Expression of angiotensin II receptors in human left and right atrial tissue in atrial fibrillation with and without underlying mitral valve disease. J Am Coll Cardiol 42: 17851792.

135. Chen YJ, Chen YC, Tai CT, Yeh $\mathrm{HI}$, Lin $\mathrm{Cl}$, et al (2006) Angiotensin and angiotensin II receptor blockermodulate the arrhythmogenic activity of pulmonary veins. Br J Pharmacol 147: 12-22.

136. Boldt A, Scholl A, Garbade J, Resetar ME, Mohr FW, et al. (2006) ACE inhibitor treatment attenuates atrial structural remodeling in patients with lone chronic atrial fibrillation. Basic Res Cardiol 101: 261-267.

137. Von Lewinski D, Kockskamper J, Rubertus SU, Zhu D, Schmitto JD, et al. (2008) Direct pro-arrhythmogenic effects of angiotensin II can be suppressed by AT1 receptor blockade in human atrialmyocardium. Eur J Heart Fail 10: $1172-1176$

138. Schneider MP, Hua TA, Bohm M, Wachtell K, Kjeldsen SE, et al. (2010) Prevention of atrial fibrillation byRenin-Angiotensin system inhibition a metaanalysis. J Am Coll Cardiol 55: 2299-2307.

139. Ruggenenti $P$, Cravedi $P$, Remuzzi $G$ (2010) The RAAS in the pathogenesis and treatment of diabetic nephropathy. Nat Rev Nephrol 6: 319-330.

140.Wolf G, Ritz E (2005) Combination therapy with ACE inhibitors and angiotensin II receptor blockers to halt progression of chronic renal disease: pathophysiology and indications. Kidney Int 67: 799-812.

141.Pfeffer MA, Swedberg K, Granger CB, Held P, McMurray JJ, et al. (2003) Effects of candesartan on mortality and morbidity in patients with chronic heart failure: the CHARM-Overall programme. Lancet 362: 759-766.

142. Yusuf S, Teo KK, Pogue J, Dyal L, Copland I, et al. (2008) Telmisartan, ramipril, or both in patients at high risk for vascular events. N Engl J Med 358 1547-1559.

143. Bomback AS, Klemmer PJ (2007) The incidence and implications of aldosterone breakthrough. Nat Clin Pract Nephrol 3: 486-492.

144. Bertocchio JP, Warnock DG, Jaisser F (2011) Mineralocorticoid receptor activation and blockade: an emerging paradigm in chronic kidney disease. Kidney Int 79: 1051-1060.

145. Weber MA (2001) Vasopeptidase inhibitors. Lancet 358: 1525-1532.

146. Burnett JC (1988) The atrial peptide system in cardiac disease. Am J Hypertens 1: S410-S420

147. Gerbes AL, Vollmar AM (1990) Degradation and clearance of atrial natriuretic factors (ANF). Life Sci 47: 1173-1180.

148. Regamey F, Maillard M, Nussberger J, Brunner HR, Burnier M (2002) Rena hemodynamic and natriuretic effects of concomitant angiotensin-converting enzyme and neutral endopeptidase inhibition in men. Hypertension 40: 266272.

149. Benigni A, Zoja C, Zatelli C, Corna D, Longaretti L, et al. (2004) Vasopeptidase 
Citation: Macia-Heras M, Del Castillo-Rodriguez N, Navarro González JF (2012) The Renin-Angiotensin-Aldosterone System in Renal and Cardiovascular Disease and the Effects of its Pharmacological Blockade. J Diabetes Metab 3:171. doi:10.4172/2155-6156.1000171

inhibitor restores the balance of vasoactive hormones in progressive nephropathy. Kidney Int 66: 1959-1965.

150. Corti R, Burnett JC, Rouleau JL, Ruschitzka F, Luscher TF (2001) Vasopeptidase inhibitors: a new therapeutic concept in cardiovascular disease? Circulation 104: 1856-1862.

151. Kostis JB, Packer M, Black HR, Schmieder R, Henry D, et al. (2004) Omapatrilat and enalapril in patients with hypertension: the Omapatrilat Cardiovascular Treatment vs Enalapril (OCTAVE) trial. Am J Hypertens 17: 103-111.

152. Prisant LM (2001) Angioneurotic edema. J Clin Hypertens 3: 262-263.

153. Northridge DB, Newby DE, Rooney E, Norrie J, Dargie HJ, et al. (1999) Comparison of the short-term effects of candoxatril, an orally active neutral endopeptidase inhibitor, and frusemide in patients with chronic heart failure. Am Heart J. 38: 1149-1157.

154.Perlini S (2005) The potential advantage of omapatrilat: dual anti-fibrotic and anti-inflammatory effects in one single molecule. J Hypertens 23: 273-255.

155. Fisher ND, Hollenberg NK (2005) Renin inhibition: What are the therapeutic opportunities? J Am Soc Nephrol 16: 592-599

156. Riccioni O, Vitulano N, D'Orazio N, Bellocci F (2009) Aliskiren, the first approved renin inhibitor: clinical application and safety in the treatment of hypertension. Adv Ther 26: 700-710.

157.Parving HH, Persson F, Lewis JB, Lewis EJ, Hollenberg NK, et al. (2008) Aliskiren combined with losartan in type 2 diabetes and nephropathy. N Eng J Med 358: 2433-2446.

158. Persson F, Lewis J, Lewis EJ, Rossing P, Hollenberg NK, et al. (2011) Aliskiren in Combination with Losartan Reduces Albuminuria Independent of Baseline Blood Pressure in Patients with Type 2 Diabetes and Nephropathy. Clin J Am Soc Nephrol 6: 1025-1031.

159. Fisher NDL, Jan Danser AH, Nussberger J, Dole WP, Hollenberg NK (2008) Renal and hormonal responses to direct renin inhibition with aliskiren in healthy humans. Circulation 117: 3199-3205.

160. Feldman DL (2010) New insights into the renoprotective actions of the renin inhibitor aliskiren in experimental renal disease. Hypertens Res 33: 279-287.

161. Danser AHJ, Boomsma F, Frandsen E, Parving H-H (2009) Renal effects of aliskiren compared with and in combination with irbesartan in patients with type 2 diabetes, hypertension, and albuminuria. Diabetes Care 32: 1873-1879.

162. Latini R, Masson S, Anand I, Salio M, Hester A, et al. (2004) Val-HeFT Investigators. The comparative prognostic value of plasma neurohormones at baseline in patients with heart failure enrolled in Val-HeFT. Eur Heart J 25 292-299.

163. Seed A, Gardner R, McMurray J, Hillier C, Murdoch D, et al. (2007) Neurohumoral effects of the new orally active renin inhibitor, aliskiren, in chronic heart failure. Eur J Heart Fail 9: 1120-1127.

164. Stanton A, Jensen C, Nussberger J, O'Brien E (2003) Blood pressure lowering in essential hypertension with an oral renin inhibitor, aliskiren. Hypertension 42: 1137-1143.

165. Solomon DS, Appelbaum E, Manning WJ, Verma A, Berglund T, et al. (2009) Effect of the direct renin inhibitor aliskiren, the angiotensin receptor blocke losartan, or both on left ventricular mass in patients with hypertension and left ventricular hypertrophy. Circulation 119: 530-537.

166. Krum H (2008) Role of renin in heart failure and therapeutic potential of direct renin inhibition. J Renin Angiotensin Aldosterone Syst 9: 177-180.

167. Parving HH, Brenner BM, McMurray JJ, de Zeeuw D, Haffner SM, et al. (2009) Aliskiren Trial in Type 2 Diabetes Using Cardio-Renal Endpoints (ALTITUDE): rationale and study design. Nephrol Dial Transplant 24: 1663-1671.

168. McMurray JJ, Pitt B, Latini R, Maggioni AP, Solomon SD, et al. (2008) Effects of the oral direct renin inhibitor aliskiren in patients with symptomatic heart failure. Circ Heart Fail 1: 17-24.

169. Frishman WH, Stier CT (2004) Aldosterone and aldosterone antagonism in systemic hypertension. Curr Hypertens Rep 6: 195-200.

170. Hollenberg NK (2004) Aldosterone in the development and progression of renal injury. Kidney Int 66: 1-9.

171. Quinkler M, Zehnder D, Eardley KS, Lepenies J, Howie AJ, et al. (2005) Increased expression of mineralocorticoid effector mechanisms in kidney biopsies of patients with heavy proteinuria. Circulation 112: 1435-1443.
172. Delyani JA (2000) Mineralocorticoid receptor antagonists: the evolution of utility and pharmacology. Kidney Int 57: 1408-1411

173. Pitt B, Remme W, Zannad F, Neaton J, Martinez F, et al. (2003) Eplerenone, a selective aldosterone blocker, in patients with left ventricular dysfunction after myocardial infarction. N Engl J Med 348: 1309-1321.

174.Zannad F, McMurray JJV, Krum H, van Veldhuisen DJ, Swedberg K, et al (2010) Eplerenone in patients with systolic heart failure and mild symptoms. N Engl J Med 364: 11-21.

175. Pitt B, Reichek N, Willenbrock R, Zannad F, Phillips RA, et al. (2003) Effects of eplerenone, enalapril, and eplerenone/enalapril in patients with essential hypertension and left ventricular hypertrophy: the 4E-left ventricular hypertrophy study. Circulation 108: 1831-1838.

176. Schjoedt KJ, Andersen S, Rossing P, Tarnow L, Parving HH, et al. (2004) Aldosterone escape during blockade of the renin-angiotensin-aldosterone system in diabetic nephropathy is associated with enhanced decline in glomerular filtration rate. Diabetologia 47: 1936-1939.

177. Navaneethan SD, Nigwekar SU, Sehgal AR, Strippoli GFM (2009) Aldosterone antagonists for preventing the progression of chronic kidney disease: a systematic review and meta-analysis. Clin J Am Soc Nephrol 4: 542-551.

178. Chrysostomou A, Becker G (2001) Spironolactone in addition to ACE inhibition to reduce proteinuria in patients with chronic renal disease. N Engl J Med 345 925-926.

179. Rachmani R, Slavachevsky I, Amit M, Levi Z, Kedar Y, et al. (2004) The effect of spironolactone, cilazapril and their combination on albuminuria in patients with hypertension and diabetic nephropathy is independent of blood pressure reduction: a randomized controlled study. Diabet Med 21: 471-475.

180.Bianchi S, Bigazzi R, Campese VM (2005) Antagonists of aldosterone and proteinuria in patients with CKD: an uncontrolled pilot study. Am J Kidney Dis 46: $45-51$.

181. Takebayashi K, Matsumoto S, Aso Y, Inukai T (2006) Aldosterone blockade attenuates urinary monocyte chemoattractant protein-1 and oxidative stress in patients with type 2 diabetes complicated by diabetic nephropathy. $\mathrm{J}$ Clin Endocrinol Metab 91: 2214-2217.

182. Epstein M, Williams GH, Weinberger M, Lewin A, Krause S, et al. (2006) Selective aldosterone blockade with eplerenone reduces albuminuria in patients with type 2 diabetes. Clin J Am Soc Nephrol 1: 940-951.

183. Bomback AS, Kshirsagar AV, Amamoo MA, Klemmer PJ (2008) Change in proteinuria after adding aldosterone blockers to ACE inhibitors or angiotensin receptor blockers in CKD: a systematic review. Am J Kidney Dis 51: 199-211.

184. Ando K, Ohtsu H, Arakawa Y, Kubota K, Yamaguchi T, et al. (2010) Rationale and design of the Eplerenone combination Versus conventional Agents to Lower blood pressure on Urinary Antialbuminuric Treatment Effect (EVALUATE) trial: a double-blinded randomized placebo-controlled trial to evaluate the antialbuminuric effects of an aldosterone blocker in hypertensive patients with albuminuria. Hypertens Res 33: 616-621.

185. Schepkens H, Vanholder R, Billiouw JM, Lameire N (2001) Life-threatening hyperkalemia during combined therapy with angiotensin-converting enzyme inhibitors and spironolactone: an analysis of 25 cases. Am J Med 110: 438 441.

186. Miao Y, Dobre D, Heerspink HJ, Brenner BM, Cooper ME, et al. (2010) Increased serum potassium affects renal outcomes: a post hoc analysis of the Reduction of Endpoints in NIDDM with the Angiotensin II Antagonist Losartan (RENAAL) trial. Diabetologia 54: 44-50.

187.Epstein M (2003) Aldosterone receptor blockade and the role of eplerenone: evolving perspectives. Nephrol Dial Transplant 18: 1984-1992.

188. Ku E, Park J, Vidhun J, Campese V (2009) The Hazards of Dual ReninAngiotensin Blockade in Chronic Kidney Disease. Arch Intern Med 169: 10151018.

189. Haynes R, Mason P, Rahimi K, Landray MJ (2009) Dual blockade of the renin-angiotensin system: are two better than one? Nephrol Dial Transplant 24: 3602-3607

190. Turnbull F, Neal B, Pfeffer M, Kostis J, Algert C, et al. (2007) Blood pressuredependent and independent effects of agents that inhibit the renin-angiotensin system. J Hypertens 25: 951-958.

191.Doulton TW, He FJ, MacGregor GA (2005) Systematic review of combined 
Citation: Macia-Heras M, Del Castillo-Rodriguez N, Navarro González JF (2012) The Renin-Angiotensin-Aldosterone System in Renal and Cardiovascular Disease and the Effects of its Pharmacological Blockade. J Diabetes Metab 3:171. doi:10.4172/2155-6156.1000171

angiotensin-converting enzyme inhibition and angiotensin receptor blockade in hypertension. Hypertension 45: 880-886

192. Nishizaka MK, Zaman MA, Calhoun DA (2003) Efficacy of low-dose spironolactone in subjects with resistant hypertension. Am J Hypertens 16: 925-930.

193. Geiger H, Barranco E, Gorostidi M, Taylor A, Zhang X, et al. (2009) Combination therapy with various combinations of aliskiren, valsartan, and hydrochlorothiazide in hypertensive patients not adequately responsive to hydrochlorothiazide alone. J Clin Hypertens (Greenwich) 11: 324-332.

194. Lee VC, Rhew DC, Dylan M, Badamgarav E, Braunstein GD, et al. (2004) Meta-analysis: angiotensin-receptor blockers in chronic heart failure and highrisk acute myocardial infarction. Ann Intern Med 141: 693-704.

195. McMurray JJ, Ostergren J, Swedberg K, Granger CB, Held P, et al. (2003) Effects of candesartan in patients with chronic heart failure and reduced leftventricular systolic function taking angiotensin-converting-enzyme inhibitors: the CHARM-Added trial. Lancet 362: 767-771.

196. Phillips CO, Kashani A, Ko DK, Francis G, Krumholz HM (2007) Adverse effects of combination angiotensin II receptor blockers plus angiotensin-converting enzyme inhibitors for left ventricular dysfunction: a quantitative review of data from randomized clinical trials. Arch Intern Med 167: 1930-1936.

197. Jessup M, Abraham WT, Casey DE, Feldman AM, Francis GS, et al. (2009) 2009 focused update: ACCF/AHA Guidelines for the Diagnosis and Management of Heart Failure in Adults: a report of the American College of Cardiology Foundation/American Heart Association Task Force on Practice Guidelines: developed in collaboration with the International Society for Heart and Lung Transplantation. Circulation 119: 1977-2016.

198. Mann JF, Schmieder RE, McQueen M, Dyal L, Schumacher H, et al. (2008) Renal outcomes with telmisartan, ramipril, or both, in people at high vascular risk (the ONTARGET study): a multicentre, randomised, double-blind, controlled trial. Lancet $372 \cdot 547-553$.

199. Furumatsu Y, Nagasawa Y, Tomida K, Mikami S, Kaneko T, et al. (2008) Effect of renin-angiotensin-aldosterone system triple blockade on nondiabetic renal disease: addition of an aldosterone blocker, spironolactone, to combination treatment with an angiotensin-converting enzyme inhibitor and angiotensin II receptor blocker. Hypertens Res 31: 59-67.

200. Vogt L, Waanders F, Boomsma F, de Zeeuw D, Navis G (2008) Effects of dietary sodium and hydrochlorothiazide on the antiproteinuric efficacy of losartan. J Am Soc Nephrol 19: 999-1007.

201.Doorenbos CR, van den Born J, Navis G, de Borst MH (2009) Possible renoprotection by vitamin $\mathrm{D}$ in chronic renal disease: beyond mineral metabolism. Nat Rev Nephrol 5: 691-700.

202. Li YC, Kong J, Wei M, Chen ZF, Liu SQ, et al. (2002) 1,25-Dihydroxyvitamin $D(3)$ is a negative endocrine regulator of the renin-angiotensin system. $J$ Clin Invest 110: 229-238.

203. Deb DK, Sun T, Wong KE, Zhang Z, Ning G, et al. (2010) Combined vitamin $\mathrm{D}$ analog and AT1 receptor antagonist synergistically block the development of kidney disease in a model of type 2 diabetes. Kidney Int 77: 1000-1009.

204. Agarwal R, Acharya M, Tian J, Hippensteel RL, Melnick JZ, et al. (2005) Antiproteinuric effect of oral paricalcitol in chronic kidney disease. Kidney In 68: $2823-2828$

205. Alborzi P, Patel NA, Peterson C, Bills JE, Bekele DM, et al. (2008) Paricalcito reduces albuminuria and inflammation in chronic kidney disease: a randomized double-blind pilot trial. Hypertension 52: 249-255.

206. Szeto CC, Chow KM, Kwan BC, Chung KY, Leung CB, et al. (2008) Ora calcitriol for the treatment of persistent proteinuria in immunoglobulin $A$ nephropathy: an uncontrolled trial. Am J Kidney Dis 51: 724-731.

207. Fishbane S, Chittineni H, Packman M, Dutka P, Ali N, et al. (2009) Ora paricalcitol in the treatment of patients with $\mathrm{CKD}$ and proteinuria: a randomized trial. Am J Kidney Dis 54: 647-652.

208. De Zeeuw D, Agarwal R, Amdahl M, Audhya P, Coyne D, et al. (2010) Selective vitamin $\mathrm{D}$ receptor activation with paricalcitol for reduction of albuminuria in patients with type 2 diabetes (VITAL study): a randomised controlled trial. Lancet 376: 1543-1551.

209. Agarwal $R$ (2010) Are vitamin D receptor agonists like angiotensin-converting enzyme inhibitors without side effects? Kidney Int 77: 943-945.
210. Stevinkel P, Ketteles M, Johnson R, Lindholm B, Pecoits-Filho R, et al. (2005) IL-10, IL-6, and TNF- $\alpha$ : central factors in the altered cytokine network of uremia-The good, the bad, and the ugly. Kidney Int 67: 1216-1233.

211. Navarro-González JF, Mora-Fernández C (2008) The role of inflammatory cytokines in diabetic nephropathy. J Am Soc Nephrol 19: 433-442.

212. Marchesi C, Paradis P, Schiffrin EL (2008) Role of the renin-angiotensin system in vascular inflammation. Trends Pharmacol Sci 29: 367-374.

213. Medzhitov R, Horng T (2009) Transcriptional control of the inflammatory response. Nat Rev Immunol 9: 692-703.

214. Benigni A, Cassis P, Remuzzi G (2010) Angiotensin II revisited: new roles in inflammation, immunology and aging. EMBO Mol Med 2: 247-257.

215. Dai Q, Xu M, Yao M, Sun B (2007) Angiotensin AT1 receptor antagonists exer anti-inflammatory effects in spontaneously hypertensive rats. $\mathrm{Br} \mathrm{J}$ Pharmacol 152: $1042-1048$.

216. Donadelli R, Abbate M, Zanchi C, Corna D, Tomasoni S, et al. (2000) Protein traffic activates NF-KB gene signaling and promotes MCP-1-dependen interstitial inflammation. Am J Kidney Dis 36: 1226-1241.

217. Remuzzi G, Zoja C, Gagliardini E, Corna D, Abbate M, et al. (1999) Combining an antiproteinuric approach with mycophenolate mofetil fully suppresses progressive nephropathy of experimental animals. J Am Soc Nephrol 10 $1542-1549$

218. Yang J, Jiang H, Ding JW, Chen LH, Li S, et al. (2009) Valsartan preconditioning protects against myocardial ischemia-reperfusion injury through TLR4/NF kappaB signaling pathway. Mol Cell Biochem 330: 39-46.

219. Jurewicz M, McDermott DH, Sechler JM, Tinckam K, Takakura A, et al. (2007) Human T and natural killer cells possess a functional renin-angiotensin system: further mechanisms of angiotensin II-induced inflammation. J Am Soc Nephrol 18: 1093-1102

220. Madhur MS, Lob HE, McCann LA, Iwakura Y, Blinder Y, et al. (2010) Interleukin 17 promotes angiotensin II-induced hypertension and vascular dysfunction. Hypertension 55: 500-507.

221. Wu L, Iwai M, Nakagami H, Li Z, Chen R, et al. (2001) Roles of angiotensin II type 2 receptor stimulation associated with selective angiotensin II type 1 receptor blockade with valsartan in the improvement of inflammation-induced vascular injury. Circulation 104: 2716-2721.

222. Vongpatanasin W, Thomas GD, Schwarts R, Cassis LA, Osborne-Lawrence $S$ et al. (2007) C-reactive protein causes downregulation of vascular angiotensin subtype 2 receptors and systolic hypertension in mice. Circulation 115: 1020 1028

223. Rompe F, Artuc M, Hallberg A, Alterman M, Stroder K, et al. (2010) Direct angiotensin II type 2 receptor stimulation acts anti-inflammatory through epoxyeicosatrienoic acid and inhibition of nuclear factor kappaB. Hypertension 55: 924-931.

224. Gelosa P, Pignieri A, Fandrilks L, de Gasparo M, Hallberg A, et al. (2009) Stimulation of AT2 receptor exerts beneficial effects in stroke-prone rats: focus on renal damage. J Hypertens 27: 2444-2451.

225. Anderson P, Cederholm T, Johanson AS, Palmblad J (2002) Captopri impaired TNF- $\alpha$ induced $\mathrm{L}-1$ production in human monocytes is associated with altered intracellular distribution of NF-KB. J Clin Lab Med 140: 103-109.

226. Stevinkel P, Anderson A, Wang T, Lindholm B, Bergstrom J, et al. (1999) Do ACE-inhibitors supress tumor necrosis factor- a production in advanced chronic renal failure? J Int Med 246: 503-507.

227. Anker SD, Negassa A, Coats AJ, Afzal R, Poole-Wilson PA, et al. (2002) Prognostic importance of weight loss in chronic heart failure and the effect of treatment with angiotensin-converting-enzyme inhibitors: An observational study. Lancet 361: 1077-1083.

228. Navarro-González JF, Mora-Fernández C, Muros de Fuentes M, GarcíaPérez J (2011) Inflammatory molecules and pathways in the pathogenesis of diabetic nephropathy. Nat Rev Nephrol 7: 327-340.

229. Navarro JF, Mora C, Macía M, García J (2003) Inflammatory parameters are independently associated with urinary albumin excretion in type 2 diabetes mellitus. Am J Kidney Dis 42: 53-61.

230. Abbate M, Zoja C, Remuzzi G (2006) How does proteinuria cause progressive renal damage? J Am Soc Nephrol 17: 2974-2984. 
Citation: Macia-Heras M, Del Castillo-Rodriguez N, Navarro González JF (2012) The Renin-Angiotensin-Aldosterone System in Renal and Cardiovascular Disease and the Effects of its Pharmacological Blockade. J Diabetes Metab 3:171. doi:10.4172/2155-6156.1000171

231.Lee FT, Cao Z, Long DM, Panagiotopoulos S, Jerums G, et al. (2004) Interactions between angiotensin II and NF-KB-dependent pathways in modulating macrophage infiltration in experimental diabetic nephropathy. $J$ Am Soc Nephrol 15: 2139-2151.

232. Han SY, Kim CH, Kim HS, Jee YH, Song HK, et al. (2006) Spironolactone prevents diabetic nephropathy through an anti-inflammatory mechanism in type 2 diabetic rats. J Am Soc Nephrol 17: 1362-1372.

233. Roozbeh J, Banihashemi MA, Ghezlou M, Afshariani R, Salari S, et al. (2010) Captopril and combination therapy of captopril and pentoxifylline in reducing proteinuria in diabetic nephropathy. Ren Fail 32: 172-178.

234. Navarro JF, Mora C, Muros M, García J (2005) Additive antiproteinuric effect of pentoxifylline in patients with type 2 diabetes under angiotensin II receptor blockade: a short-term, randomized, controlled trial. J Am Soc Nephrol 16 2119-2126.

235. Kunz R, Bork JP, Fritsche L, Ringel J, Sharma AM (1998) Association between the angiotensin-converting enzyme-insertion/deletion polymorphism and diabetic nephropathy: A methodological appraisal and systematic review. J Am Soc Nephrol 9: 1653-1663.

236. Spielman RS, McGinnis RE, Ewens WJ (1993) Transmission test for linkage disequilibrium: the insulin gene region and insulin dependant diabetes mellitus (IDDM). Am J Hum Genet 52: 506-516.

237. Ruggenenti P, Bettinaglio P, Pinares F, Remuzzi G (2008) Angiotensin converting enzyme insertion/deletion polymorphism and renoprotection in diabetic and nondiabetic nephropathies. Clin J Am Soc Nephrol 3: 1511-1525.

238. Rudnicki M, Mayer G (2009) Significance of genetic polymorphisms of the renin-angiotensin-aldosterone system in cardiovascular and renal disease. Pharmacogenomics 10: 463-476

239. Martinez Vea A (2002) Polimorfismos del sistema renina-angiotensina en insuficiencia renal. Nefrologia 22: 89-94.

240.Taal MW (2000) Angiotrensin-converting enzyme gene polymorphisms in renal disease: clinically relevant? Curr Opin Nephrol Hypertens 9: 651-657.

241. Marre M (1999) Genetics and the prediction of complications in type 1 diabetes. Diabetes Care 22: B53-B58.

242. Miller JA, Thaik K, Scholey JW (1999) Angiotensin type 1 receptor gene polymorphism predicts response to losartan and angiotensin II. Kidney Int 56: 2173-2180.

243. Perna A, Ruggenenti P, Teta A, Spoto B, Benini R, et al. (2000) Grupo italiani di study epidemiologici in nefrologia (GINSEN): ACE genotype and ACE inhibitors induce renoprotection in chronic proteinuric nephropaties. Kidney Int 57: 274-281.
244. Pontremoli R, Ravera M, Viazzi F, Nicolella C, Berruti V, et al. (2000) Genetic polymorphisms of the renin-angiotensin system and organ damage in essentia hypertension. Kidney Int 57: 561-569.

245. Ruggenenti P, Perna A, Zoccali C, Gherardi G, Benini R, et al. (2000) Chronic proteinuric nephropathies. II Outcomes and response to treatment in a prospective cohort of 352 patients: Differences between women and men in relation to the ACE gene polymorphism. J Am Soc Nephrol 11: 88-96.

246. Humma LM, Terra SG (2002) Pharamacogenetics and cardiovascula disease: impact on drug response and applications to disease management. Am J Health-Syst Pharm 59: 1241-1252.

247. Farahani P, Dolovich L, Levine M (2007) Exploring design-related bias in clinical studies on receptor genetic polymorphism of hypertension. J Clin Epidemiol 60: 1-7.

248. Konoshita T (2011) Do Genetic Variants of the Renin-Angiotensin System Predict Blood Pressure Response to Renin-Angiotensin System-Blocking Drugs? A Systematic Review of Pharmacogenomics in the Renin-Angiotensin System. Curr Hypertens Rep 13: 356-361.

249. Henry D, Lexchin J (2002) The pharmaceutical industry as a medicine provider. Lancet 369: 1590-1595.

250. Coast J (2004) Is economic evaluation in touch with society's health values? BMJ 329: 1233-1236.

251. Trivedi HS, Pang MMH, Campbell A, Saab P (2002) Slowing the progression of chronic renal failure: Economic benefits and patients' perspectives. Am J Kidney Dis 39: 721-729.

252. Campbell RC, Ruggenenti P, Remuzzi G (2002) Halting the Progression of Chronic Nephropathy J Am Soc Nephrol 13: S190-S195.

253. Abbate M, Remuzzi G (2003) Can We Really Lessen Kidney Damage to the Point that the Loss of Renal Function of Progressive Nephropathy May Revert? J Am Soc Nephrol 14: 1411-1414.

254. National High Blood Pressure Education Program (2004) National Heart Lung and Blood Institute. The seventh report of the Joint National Committee on Prevention, Detection, Evaluation and Treatment of High Blood Pressure.

255. National Institute for Health and Clinical Excellence. Hypertension: management of hypertension in adults in primary care. Clinical guideline 34 2006

256. Mitch WE (2004) Treating diabetic nephropathy-are there only economic issues? N Eng J Med 351: 1934-1936.

257. Schieppati A, Remuzzi G (2004) Fighting renal diseases in poor countries: building a global fund with the help of the pharmaceutical industry. J Am Soc Nephrol 15: 704-707. 